\title{
CONSIDERACIONES EN TORNO A LA DISTINCIÓN ENTRE EL FONDO Y LA FORMA EN EL DERECHO INTERNACIONAL (PÚBLICO Y PRIVADO)
}

\author{
Ricardo Gosalbo Bono* \\ «Il est plus facile de légaliser certaines choses que de les légitimer»***
}

SUMARIO: 1 . INTRODUCCIÓN.-2. FONDO Y FORMA EN DERECHO INTERNACIONAL PÚBLICO.-2.1. La génesis informal de las fuentes del Derecho internacional.-2.2. El desafío formalista de la reciente jurisprudencia internacional.-2.3. Sobre la inutilidad e inconveniencia de establecer criterios estancos en la distinción entre fondo y forma.-3. EL DECLIVE DE LA NORMA LEX FORI REGIT PROCESSUM.-3.1. La crisis de la distinción entre consuetudo ad litem decidendam y consuetudo ad litis ordinationem introducta.-3.2. Fondo y forma en la calificación.-3.3. Fondo y forma en la aplicación de la ley extranjera.-3.4. La conflictualización de la lex fori regit processum.-4. CONCLUSIONES.

\section{INTRODUCCIÓN}

1. Durante más de un siglo, legisladores, jueces y juristas han intentado vanamente establecer una línea de división clara entre el fondo (Derecho sustantivo o material que regula los derechos y las obligaciones de los sujetos de Derecho) y la forma (Derecho adjetivo o procesal relativo a los enjuiciamientos, los procedimientos y en general la Administración de justicia) ${ }^{1}$.

2. En las páginas que siguen analizaré los pasos recientes que sobre la cuestión han dado la abundante bibliografía y la no menos importante jurisprudencia, tanto en Derecho internacional (DI) público como en DI pri-

* Professor of Law, Vrije Universiteit Brussel, PhD. (Cantab.), Doctor en Derecho. Antiguo Director en el Servicio Jurídico del Consejo de la Unión Europea (UE). Las opiniones vertidas en estas páginas son estrictamente personales.ricardo.gosalbo@hotmail.com.

** De Chamfort, N., Maximes et pensées, caractères et anecdotes, París, Les éditions G. Grès, 1923, máxima CXXXIV.

1 CAPpelletti, M. y Garth, B., «Substantive law and procedural law», Enciclopaedya of Comparative Law, vol. 16, 1987, Capítulo 1, p. 14; y LindBLOM, H., "On the distinction between procedural and substantive law», Escandinavian studd. L., vol. 18, 1984, pp. 111-149. 
vado. También recurro al método comparativo y a la historia del Derecho cuando así lo exija la clarificación de argumentos y resultados. Mi estudio no pretende ofrecer, ni mucho menos, una reflexión acabada y completa de esta importante y compleja cuestión. El objetivo es mucho más modesto y se limita a enhebrar algunas reflexiones, habitualmente orilladas, omitidas o tergiversadas, sobre si verdaderamente existe en la actualidad una razón en la distinción entre sustancia y procedimiento, si es posible establecer una clasificación general o si el contenido de la distinción únicamente puede ser elucidado casuísticamente.

\section{FONDO Y FORMA EN DERECHO INTERNACIONAL PÚBLICO}

3. La primera idea que debemos retener es que distinción entre fondo y forma fundamenta la diferenciación entre el DI público y el Derecho interno. Aquel no se distingue de este por el fondo, es decir, en razón al contenido o la sustancia pues ambos cubren las mismas cuestiones sustanciales. La singularidad del DI público respecto al Derecho interno se debe a la forma, por haber sido producido de determinada manera por los sujetos del DI público.

4. Históricamente, los sujetos internacionales elaboraron normas de DI público cuando se dio la condición de igualdad formal (que no igualdad territorial o de poder) entre ellos para poder concertarse por medio de acuerdos. Tal situación se remonta a la aparición en el Oriente Medio, alrededor del siglo Xv a. C., de una serie de entidades independientes (Egipto, Babilonia, los reinos Hitita y de Mitani y el imperio Asirio) que se renonocían mutuamente la igualdad entre sus gobernantes como fundamento para establecer un sistema de relaciones internacionales y plasmarlas en acuerdos de paz, asistencia mutua y extradición. La antigua Grecia de las ciudades-Estado autónomas e independientes que se desarrolló entre los siglos VII y VI a. C. no solo se adhirió a este sistema sino que lo desarrolló aportando el arbitraje como método informal de arreglo de controversias.

5. Estas condiciones no se dieron ni en el imperio chino ni en el imperio romano, puesto que ambos afirmaron su superioridad sobre las entidades con las que se relacionaron, lo que imposibilitó el desarrollo de un DI público fundamentado en el principio de la igualdad formal entre sujetos. En particular, la Antigua Roma condicionó las relaciones y actuaciones con otros pueblos al cumplimiento, controlado por el collegium de los sacerdotes feciales, de una serie de formalismos, rituales, solemnidades, ceremonias, juramentos, invocaciones a Júpiter, y ritos procesales secretos de naturaleza religiosa y sagrada que daban solemnidad a la seriedad de la palabra dada (bona fides), la firma de tratados internacionales o la declaración de la guerra ${ }^{2}$, al ser impuestos por el fas o Derecho divino vinculante universalmente. La necesidad

\footnotetext{
2 El requerimiento de una restitución o reparación exigía el ritual de la rerum repetition. La firma de un tratado se realizaba mediante la fórmula del ius iurandum ante Júpiter. Y la declaración de guerra estaba precedida por el ceremonial de la afirmación de la naturaleza justa y pía de la contienda
} 
del cumplimiento de rituales y formalismos en el plano externo concordaba con la preeminencia de la forma sobre el fondo en el plano interno, que imponía el ius Quiritium aplicable a los ciudadanos romanos al disponer que todo acto jurídico que creara, modificara o extinguiera derechos u obligaciones (el fondo) debía corresponderse con una determinada Actio o recurso (la forma) que posibilitara la defensa y reclamación de tal derecho u obligación ${ }^{3}$.

La flexibilización de este rígido formalismo vino hacia el año 242 a. C., a través de los edictos del praetor peregrinus, el magistrado encargado de administrar libremente justicia a los extranjeros (peregrini) que estaban desasistidos de la protección que el ius civile otorgaba a los ciudadanos romanos y que constituían, en el seno de la ciudad, un mundo jurídico aparte con usos y negocios jurídicos propios y no formales. El magistrado creó con su edicto un ius honorarium equitativo e informal, aplicable a los extranjeros, que no se detenía en las fronteras y tuvo por fuente el libre imperio del pretor y la tradición/costumbre (ius gentium). Por una parte, se desformalizaron algunas instituciones del ius civile (la simple entrega/traditio se convierte en modo válido de adquirir la propiedad de cosas nec mancipi). Y, por otra parte, se incorporaron los principios del ius commercii vigentes en centros distintos de los romanos abriendo el cauce a los negocios libres, propios del tráfico jurídico y accesibles por igual a nacionales y extranjeros. De esta forma, en las postrimerías de la época republicana, el Derecho de la ciudad de Roma va adquiriendo, decididamente, la fisonomía informal del Derecho universal del porvenir.

\subsection{La génesis informal de las fuentes del Derecho internacional}

6. La propia génesis de las fuentes del DI público moderno evidencia su singular informalidad (carácter no formalista del consentimiento) ${ }^{4}$.

7. En el marco del Derecho de los tratados, el Tribunal Internacional de Justicia (TIJ) ha consagrado la validez jurídica de los acuerdos internacionales concertados de cualquier forma o bajo cualquier denominación siempre que supongan un acuerdo de voluntades entre sujetos de DI y estén gobernados por el DI público: un «acuerdo internacional puede tener formas variadas y presentarse bajo denominaciones diversas ${ }^{5}$. Lo que caracteriza a un tratado es la sustancia, la naturaleza del acto o transacción contenida en el mismo y no la forma, siendo posible incluso la forma verbal ${ }^{6}$. El propio Convenio de Viena sobre el Derecho de los tratados ha simplificado considerablemente el proceso de celebración de los tratados introduciendo la presunción de plenos

(bellum iustum piumque). Algunas de estas fórmulas aparecen descritas por Tito Livio en Historia de Roma, Libro I, Arabako Foru Aldundia, 2006, p. 32.

3 La exigencia de rituales es característica común de todos los pueblos primitivos: véase MAINE, H. S., Ancient Law, Londres, J. Murray ed., 1908, pp. 3-11.

${ }^{4}$ Reuter, P., Droit international public, París (PUF), 5. a ed., 1976, p. 17; D’Aspremont, J., Formalism and the Sources of International Law. A Theory of the Ascertainment of Legal Rules, Oxford, Oxford University Press, 2013, pp. 154 y ss.

5 Delimitación marítima y cuestiones territoriales entre Catar y Bahréin, ICJ Reports 1994, p. 120.

6 Plataforma Continental del Mar Egeo, ICJ Reports 1978, p. 39. 
poderes (art. 7) o flexibilizando el modo de manifestación del consentimiento en obligarse (el criterio de la conservación de los actos viciados) ${ }^{7}$ (arts. 12-14).

La práctica internacional ofrece una gran variedad de acuerdos internacionales en cuanto a la forma, el grado de vinculación y la naturaleza sustancial o de procedimiento del surtido de disposiciones estructurales, vinculantes o no y de los mecanismos de supervisión y de incumplimiento establecidos en los mismos ${ }^{8}$. En general, los instrumentos consensuales que contienen obligaciones vinculantes han demostrado ser más eficaces, como es el caso de los acuerdos sobre la capa de ozono o los acuerdos sobre la Organización Mundial del Comercio (OMC). Sin embargo, la práctica demuestra que el carácter normativo o no, jurídicamente vinculante o no, de las disposiciones de un acuerdo (lo que se ha venido en llamar «hardness or softness of rules») no deriva de la forma o de la génesis del acuerdo ${ }^{9}$, como demuestran los importantes debates en torno a la naturaleza vinculante o no del Acuerdo de París de 2015 que ejecuta medidas para la reducción de las emisiones de gases de efecto invernadero dentro del Convenio marco de la Organización de las Naciones Unidas (ONU) sobre el cambio climático ${ }^{10}$.

8. La costumbre internacional es una fuente de Derecho primaria, espontánea e informal de manifestarse la comunidad internacional en cuya génesis prima no el elemento formal sino el elemento material (la repetición de actos que genera la práctica general) y el espiritual (la aceptación de dicha práctica como Derecho u opinio juris) (art. 38 del Estatuto del TIJ) ${ }^{11}$. En cuanto a la forma, la práctica puede asumir una gran variedad de configuraciones e incluye tanto actos físicos como verbales, tales como la conducta de los Estados «sobre el terreno», la correspondencia y los actos diplomáticos, la legislación, las sentencias de los tribunales nacionales, las publicaciones oficiales sobre DI público, las declaraciones formuladas en nombre de los Estados relativas a la labor de codificación, la práctica relacionada con los tratados, los actos relativos a las resoluciones de los órganos de organizaciones y conferencias internacionales e incluso la inacción de estos órganos ${ }^{12}$.

\footnotetext{
7 Garzón Clariana, G., "Libertad de forma, favor negotti y cambio en el derecho de gentes», Librohomenaje al profesor Antonio Truyol Serrra, Madrid, Universidad Complutense, 1986, p. 497.

8 Raustiala, K., «Form and Substance in International Agreements», AJIL, vol. 99, 2005, núm. 3, pp. 581-614; SCHACHTER, O., «The Twilight Existence of Nonbinding International Agreements», AJIL, vol. 71, 1977, pp. 296-304; y KLABbers, J., «The Redundancy of Soft Law», Nordic JIL, vol. 65, 1996, núm. 2, pp. 167-182.

9 Boyle, A., "Some Reflections on the Relationship of Treaties and Soft Law», ICLQ, vol. 48, 1999, núm. 4, pp. 901-912, esp. pp. 906-907; y DupuY, P.-M., "Soft Law and the International Law of the Environment», Mich. J. Intl. Law, vol. 12, 1991, núm. 2, pp. 420-435.

10 Maljean-Dubois, S., Spencer, Th. y Wemaere, M., "The Legal Form of the Paris Climate Agreement: A Comprehensive Assessment of Options», Carbon and Climate Law Rev., vol. 9, 2015, pp. 68-84. En general, los estudios empíricos sobre las obligaciones vinculantes y no vinculantes son equívocos (SCHACHTER, O., op. cit., nota 7; y KLABBERS, J., op. cit., nota 7).

11 Wood, M., "Segundo informe sobre la identificación del Derecho internacional consuetudinario", Doc. A/CN.4/672, de 22 de mayo de 2014, p. 5, párr. 14. Véase el caso de las Pesquerías (Reino Unido c. Noruega), ICJ Reports 1951, p. 131.

12 Proyecto de Conclusión núm. 7, incluida en el «Segundo informe sobre la identificación del Derecho internacional consuetudinario», op. cit., nota 10. Véase Conforti, B. y LaBella, B., An Introduction to International Law, Leiden/Boston, Brill/Nijhoff, 2012, p. 32.
} 
9. Los principios generales del Derecho internacional reconocidos y aceptados por la jurisprudencia y la doctrina (pacta sunt servanda, in dubio pro reo, ex injuria non oritur), no son en sus orígenes sino postulados de la conciencia jurídica que expresan la esencia misma del Derecho y que se generan a partir de los adagios, aforismos o apotegmas jurídicos originados en los diversos sistemas jurídicos, especialmente del Derecho romano. A pesar de constituir una de las muestras más claras y representativas de la estrecha relación e interdependencia entre el DI público y el Derecho interno ${ }^{13}$ y de ser una fuente frecuentemente utilizada por el Tribunal Permanente de Justicia Internacional (TPJI) y por el TIJ, el método utilizado en su identificación adolece de sofisticación ${ }^{14}$.

10. Los actos unilaterales pueden ser unilaterales solo en cuanto a la forma (cuando emanan de una sola manifestación de la voluntad, es decir, la declaración jurídica o compromiso formal, el instrumentum), o en cuanto al fondo y forma (el contenido sustancial de la obligación o negotium), cuando además de emanar de una sola manifestación de la voluntad, operan independientemente de cualquier otra expresión de la voluntad emitida por cualquier otro sujeto de $\mathrm{DI}^{15}$. El requisito esencial del acto unilateral internacional es la existencia de una intención «jurídica» de vincularse de conformidad con los términos de la declaración/acto unilateral de que se trate (objeto preciso $)^{16}$ y, en cuanto a la forma, su publicidad, notificación o comunicación a la comunidad internacional (en cuyo caso produce efectos erga omnes) o a las partes interesadas. Cumplidos estos requisitos, el DI público no exige una forma determinada para que surja efectos un acto unilateral y la práctica internacional así lo demuestra ${ }^{17}$.

13 Lauterpacht, H., Private Law Sources and Analogies of International Law, Handem, Archon Books, 1970, pp. 37 y 60-67.

14 Ellis, J., «General Principles and Comparative Law», EJIL, vol. 22, 2011, núm. 4, pp. 949-971. Como indicó el juez McNair se trata de un «método de filtraje» basado en el examen de las características y la terminología de normas e instituciones de Derecho privado que proporciona al DI público de «una indicación de políticas y principios» pero que descarta incorporar directamente dichas normas e instituciones internas en el DI público (opinión consultiva sobre el Estatuto Internacional del África Sudoccidental, ICJ Reports 1950, p. 148). La doctrina ha criticado abiertamente este método por tratarse de un proceso de abstracción y generalización que conduce «à s'en tenir à un essentiel de plus en plus désincarné. [...] D'une certaine manière, [...] autodestructeur»: véase WEIL, P., "Cours général de droit international public», $R C A D I$, vol. 237, 1992, pp. 9-370, esp. p. 131.

15 Véase Goodman, C., "Acta Sunt Servanda?», Australian YbIL, vol. 25, 2004, pp. 43-73.

16 Ensayos nucleares (Nueva Zelanda c. Francia), ICJ Reports 1974, p. 253, párr. 43. En el caso de las Actividades militares y paramilitares en y contra Nicaragua (Nicaragua c. Estados Unidos de América), ICJ Reports 1984, p. 392, el TIJ rechazó otorgar efectos jurídicos a la declaración del gobierno consistente en organizar elecciones libres porque, según el Tribunal, se trataba de un compromiso político que formaba parte del programa electoral.

17 Estatuto jurídico de Groenlandia Oriental, CPJI, 1933, Serie A/B, núm. 53, p. 71; Ensayos Nucleares (Australia c. Francia), ICJ Reports 1974, párr. 42 y ss.; Ensayos Nucleares (Nueva Zelanda c. Francia), ICJ Reports 1974, párrs. 45 y ss.; y Actividades armadas sobre el territorio del Congo (República Democrática del Congo c. Ruanda), ICJ Reports 2006, párr. 41. 


\subsection{El desafío formalista de la reciente jurisprudencia internacional}

11. La jurisprudencia reciente del TIJ ha introducido una preeminencia de la forma sobre el fondo en ciertos supuestos que analizamos a continuación.

En general, el TIJ se atiene a criterios formales estrictos cuando los asuntos que se le presentan plantean cuestiones que conciernen el alcance personal, espacial y temporal de su jurisdicción, competencia y el acceso a la justicia internacional. La justificación última estriba en que, a diferencia de los tribunales estatales, a los tribunales internacionales, y en particular al TIJ, ni se les ha conferido una competencia automática ("principio del oro amonedado» ${ }^{18}$ o de jurisdicción voluntaria), ni sus sentencias tienen efecto ejecutivo salvo en raras excepciones por lo que sus destinatarios gozan de un amplio margen de discrecionalidad a la hora de elegir la forma en que les dan cumplimiento, ni se insertan en un sistema único y jerarquizado en términos jurisdiccionales, ni existe una relación formalizada entre los distintos tribunales internacionales ${ }^{19}$.

12. La limitación del acceso a la justicia internacional por falta de legitimación activa o pasiva (locus standi) se ha convertido en problemática en aquellos asuntos donde se plantean cuestiones con pretensiones contrapuestas fundamentadas en la inmunidad del Estado (cuestión formal de procedimiento) y en el jus cogens (cuestión de fondo o sustancial) ${ }^{20}$.

En el caso de las Actividades armadas en el territorio del Congo ${ }^{21}$ el TIJ rechazó la pretensión de la República Democrática del Congo que invocaba la nulidad de la reserva de Ruanda a la jurisdicción del TIJ en el supuesto de violaciones del jus cogens. El TIJ estimó que una disputa relativa al cumplimiento del jus cogens internacional no puede, por sí misma, proveer una base competencial al TIJ 22 pues el jus cogens no confiere al TIJ una competencia que este no tendría de otra forma ${ }^{23}$.

En la misma línea, en el caso de las Inmunidades jurisdiccionales del Estado ${ }^{24}$ el TIJ amparó la pretensión alemana de que Italia no había respetado la inmunidad de jurisdicción de Alemania, al permitir que se entablaran demandas civiles ante los tribunales italianos que solicitaban la reparación de

\footnotetext{
18 Oro Amonedado sacado de Roma en 1943 (Italia c. Francia, Reino Unido y Estados Unidos de América), ICJ Reports 1954, p. 19.

19 Escobar Hernández, C., "Procedimientos de aplicación de las normas internacionales», en Díez DE Velasco, M., Instituciones de Derecho internacional público, Madrid, Tecnos, 2013, p. 966.

20 Véase Hanna, M., «The Substantive/Procedural Distinction: Law's Solution to the Problem of Ius Cogens in a World of Sovereign States», German Law Journal, vol. 19, 2018, pp. 21-42.

${ }_{21}$ Actividades armadas sobre el territorio del Congo (República Democrática del Congo c. Ruanda), ICJ Reports 2006, p. 6.

22 Ibid., párr. 64.

23 Ibid., párr. 125.

${ }^{24}$ Inmunidades jurisdiccionales del Estado (Alemania c. Italia: Grecia interviniente), ICJ Reports 2012, p. 99.
} 
los perjuicios causados por las violaciones del jus cogens internacional humanitario cometidas por el Reich alemán durante el periodo 1943-1945. Según el TIJ, la inmunidad del Estado y el jus cogens no pueden entrar en conflicto porque son dos conjuntos de reglas que se aplican a cuestiones diferentes: las reglas de la inmunidad del Estado son de naturaleza procesal y tienen un carácter preliminar, limitándose a determinar si los tribunales de un Estado pueden o no ejercer su competencia respecto de otro Estado. No entra en su ámbito de aplicación la cuestión de saber si la conducta respecto de la cual se incoan las actuaciones judiciales fue lícita o ilícita. Según el TIJ, si la inmunidad de jurisdicción de un Estado se determinara en función de la gravedad (jus cogens) de los delitos y violaciones cometidos (quod non), los tribunales tendrían que determinar si dichas violaciones y delitos se cometieron realmente, una cuestión que concierne al fondo del asunto, pues de otra manera una mera acusación o una presentación hábil de la reclamación bastarían por si solas para obtener la revocación de la inmunidad ${ }^{25}$.

Esta jurisprudencia internacional ha dividido a la doctrina internacional en partidarios ${ }^{26}$ y detractores ${ }^{27}$ y ha expuesto en toda su crudeza la cuestión del alcance del derecho a la realización de la justicia como conjunto unitario a la vez procesal y material del Estado de Derecho internacional: el razonamiento que considera que la unidad del jus cogens puede ser reemplazada por una diferencia que proporciona al Derecho una base para fundamentar dos normas incompatibles que intentan resolver dos situaciones de hecho distintas implica que no hay, o no puede haber, conflicto entre las normas «sustantivas» de jus cogens y las normas «procesales» de la inmunidad del Estado y esa distinción puede llevar en casos futuros a resultados que consagren de facto la inmunidad de los crímenes de lesa humanidad, los delicta imperii o a la denegación del «derecho al derecho» (droit au Droit) de las víctimas de la opresión.

13. También ha introducido el TIJ unos polémicos requisitos formales en la noción de controversia como condición de admisibilidad de una demanda.

25 Con anterioridad, fuera del contexto del jus cogens, el TEDH decidió en Al-Adsani c. Reino Unido que no existía una violación del art. 6 del CEDH relativo al derecho a un proceso equitativo, porque no pudo establecer que el DI público sancionara que un Estado no goza de inmunidad en el procedimiento civil y porque, en cualquier caso, la inmunidad no debía concebirse como cualificando un derecho sustancial o material, sino como un impedimento formal de la competencia de los tribunales nacionales para determinar ese derecho: véase Al-Adsani c. Reino Unido, núm. 35763/97, TEDH 2002. Asimismo, véase Fox, H. y WebB, Ph., The Law of State Immunity, Oxford, Oxford University Press, 2013, p. 525.

26 Talmon, S., "Ius Cogens after Germany v. Italy: Substantive and Procedural Rules Distinguished», Leiden JIL, vol. 25, 2012, núm. 4, pp. 979-1002, esp. p. 986; y Toмuschat, C., "The case of Germany v. Italy before the ICJ», en PETERs, A. et al. (eds.), Immunities in the Age of Global Constitutionalism, Leiden, Martinus Nijhoff, 2014, pp. 87-98, esp. p. 88.

27 Orakhelashvili, A., "Peremptory Norms as an Aspect of Constitutionalisation in the International Legal System», en Frishman, M. y Muller, S. (eds.), The Dynamics of Constitutionalism in the Age of Globalisation, La Haya, Asser Press, 2010, pp. 153-180, esp. p. 165; Di CiAccio, P., "A Torturer's Manifesto? Impunity through Immunity in Jones v. The Kingdom of Saudi Arabia», Sidney L. Rev., vol. 30, 2008, p. 557; BESNER, J. y ATTARAN, A., "Civil Liability in Canada's Courts for Torture Committed Abroad: the Unsatisfactory Interpretation of the State Immunity Act», Tort L. Rev., vol. 16, 2008, p. 164; y McGregor, L., «Torture and State Immunity: the Flecting Impunity, Distorting Sovereignty», EJIL, vol. 18, 2007, núm. 5, pp. 903-913, esp. p. 911. 
En su jurisprudencia constante el TIJ había establecido que «[una] controversia es un desacuerdo sobre un aspecto de derecho o de hecho, un conflicto de opiniones jurídicas o intereses entre dos personas» ${ }^{28}$ cuya existencia corresponde determinar objetivamente al TIJ sobre la base de un examen de los hechos ${ }^{29}$, lo que constituye una cuestión «de fondo, no de forma» ${ }^{30}$.

Sin embargo, en el caso de las Obligaciones respecto de las negociaciones sobre la cesación de la carrera de armamentos nucleares y el desarme nuclear ${ }^{31}$, el TIJ estimó que no tenía competencia para declarar la admisibilidad de la demanda de las Islas Marshall, que alegaba que los Estados demandados habían incumplido sus obligaciones, dimanantes del DI consuetudinario y convencional, sobre la cesación de la carrera de armamentos nucleares y el desarme nuclear. Según el TIJ, la demanda fundamentada en una controversia jurídica carecía de fundamento en ausencia de dos requisitos formales: la notificación previa de la pretensión a los Estados demandados y «las pruebas» (negociaciones diplomáticas o una explicación de voto) que demostraran «que la parte demandada sabía o no podía ignorar que la parte demandante había expresado una "oposición manifiesta" a su punto de vista»" 32 . Al introducir el cumplimiento estos elementos formales en la definición de controversia, el fallo parece contradecir la jurisprudencia constante del propio TIJ que consideraba suficiente para la existencia de una controversia el mero examen por el TIJ de todo tipo de declaraciones o documentos intercambiados por las partes, así como las conversaciones llevadas a cabo en contextos multilaterales ${ }^{33}$.

El fallo, que dividió «estructuralmente» ${ }^{34}$ a los magistrados del TIJ en dos bandos iguales (8/8) (finalmente el voto dirimente del presidente Abraham inclinó balanza), ha recibido abundantes críticas de diversa naturaleza y calado $^{35}$, principalmente por descartar la aplicación del «principio Mavrommatis» que autoriza al TIJ a prescindir de los defectos formales de la demanda cuando su amparo conduciría a la «circularidad del procedimiento» o a una situación contraria «a los intereses de la buena administración de

\footnotetext{
${ }_{28}$ Concesiones Mavrommatis en Palestina, CPJI, 1924, Serie A, núm. 2, p. 11.

29 Interpretación de los tratados de paz con Bulgaria, Hungría y Rumania, opinión consultiva, ICJ Reports 1950, p. 74.

${ }^{30}$ Aplicación de la Convención Internacional sobre la Eliminación de todas las Formas de Discriminación Racial (Georgia c. Federación de Rusia) (Excepciones Preliminares), ICJ Reports 2011, párr. 3.

31 Obligaciones respecto de las negociaciones sobre la cesación de la carrera de armamentos nucleares y el desarme nuclear (Islas Marshall c. Reino Unido, India y Pakistán), ICJ Reports 2016, p. 255.

${ }^{32}$ Ibid., párr. 41.

${ }_{33}$ Frontera terrestre y maritima entre Camerún y Nigeria (Excepciones Preliminares), ICJ Reports 1998, p. 275; y África Sudoccidental (Liberia c. África del Sur) (Etiopía c. África del Sur) (Excepciones Preliminares), ICJ Reports 1962, p. 346. Véase VEnzKe, I., «Public Interests in the International Court of Justice - A Comparison between Nuclear Arms Race (2016) and South West Africa (1966)», AJIL Unbound, vol. 111, 2017, p. 72.

${ }^{34}$ Véase BIANCHI A., "Choice and (the Awareness of) its Consequences: the ICJ's Structural Bias Strikes Again in the Marshall Islands Case», AJIL Unbound, vol. 111, 2017, pp. 81-87.

${ }_{35}$ El American Journal of International Law organizó en diciembre de 2017 un Simpósium para discutir las consecuencias del fallo del TIJ sobre el caso planteado por las Islas Marshall, cuyos resultados aparecen reflejados en el vol. 111, 2017, pp. 62 y ss.
} 
justicia» ${ }^{36}$, o, añado, de las exigencias del Estado de Derecho internacional ${ }^{37}$; y por afectar negativamente el resultado de la carga de la prueba ${ }^{38}$.

14. Todavía permanece sin resolver definitivamente la cuestión de si la norma del agotamiento de los recursos internos es de naturaleza formal o material. Calificada por el TIJ como «norma bien arraigada del Derecho internacional consuetudinario» ${ }^{39}$ y como "un importante principio» ${ }^{40}$, garantiza que «el Estado en que se causó el perjuicio pueda repararlo por sus propios medios y en el marco de su propio ordenamiento jurídico interno ${ }^{41}$. La norma opera muy especialmente en el marco de la responsabilidad internacional $^{42}$, como requisito previo para el ejercicio de la protección diplomática ${ }^{43}$, y como condición para la admisibilidad de una demanda por violación de los derechos humanos, en virtud del art. 35 del Convenio Europeo de Derechos Humanos $(\mathrm{CEDH})$. ¿Se trata de una regla práctica de puro procedimiento relativa a la manera de «hacer efectiva» la responsabilidad internacional? ¿O es una norma material de fondo que determina el nacimiento de la responsabilidad internacional? ¿O tiene más bien un carácter mixto, que funciona como norma de fondo determinando el origen de la responsabilidad cuando los órganos judiciales hayan incumplido su deber de garantizar a un particular la protección judicial internacionalmente exigida contra los daños sufridos como consecuencia de la violación del Derecho interno únicamente y, en los demás casos, funciona como norma de procedimiento destinada a hacer efectiva la responsabilidad? ${ }^{44}$.

36 Véase la opinión disidente del juez Crawford en el caso de las Obligaciones respecto de las negociaciones sobre la cesación de la carrera de armamentos nucleares y el desarme nuclear (Islas Marshall c. India), ICJ Reports 2016. Véase Concesiones Mavrommatis en Palestina, CPJI, 1924, Serie A, núm. 2.

37 Resolución 67/1, de 24 de septiembre de 2012. La Asamblea General de la ONU aprobó la Declaración de la reunión de alto nivel de la Asamblea General sobre el estado de derecho en los planos nacional e internacional. Véase CAPPELlETtI, M. y GARTH, B., "Access to Justice: the Newest Way in the Worldwide Movement to Make Rights Effective», Buff. Law. Rev, vol. 27, 1978, p. 182; ANGHIE, A., "Politic, Cautious, and Meticulous: An Introduction to the Symposium on the Marshall Islands Case», AJIL Unbound, vol. 111, 2017, pp. 62-67, esp. p. 66; y GaLINDO, G., "On Form, Substance and Equality between States», AJIL Unbound, vol. 111, 2017, pp. 75-80.

$38 \mathrm{Si}$ la carga de la prueba de la existencia de una controversia incumbe a los demandantes, carecen de valor los votos de los Estados demandados que no estuvieran acompañados por una explicación de voto, lo que confirma la idea de que la carga de la prueba no tiene nada que ver con la cuestión de fondo. Véase Foster, C., "Burden of Proof in International Courts and Tribunals», Australian YbIL, vol. 29, 2010, pp. 27-86.

39 Interhandel (Suiza c. Estados Unidos de América) (Excepciones preliminares), ICJ Reports 1959, pp. 6 y 27.

${ }^{40}$ Elettronica Sicula S.p.A. (ELSI) (Estados Unidos de América c. Italia), ICJ Reports 1989, párr. 50.

${ }^{41}$ Interhandel (Suiza c. Estados Unidos de América) (Excepciones preliminares), ICJ Reports 1959, p. 27.

42 Art. 44 del Proyecto de Artículos sobre la Responsabilidad internacional del Estado por hechos internacionalmente ilícitos: véase Anuario $C D I$, vol. 2, 2001, 2. a parte, p. 129. Véase MiAJA DE LA MUELA, A., "El agotamiento de los recursos internos como supuesto de las reclamaciones internacionales», Anuario Uruguayo de Derecho Internacional, vol. 2, 1963, pp. 9-58.

43 Arts. 14-15 del Proyecto de Artículos sobre la Protección Diplomática: véase Anuario CDI, vol. 2, 2006, 2. ${ }^{\text {a }}$ parte, pp. 22-23.

${ }^{44}$ FawcetT, J., «The Exhaustion of Local Remedies: Substance or Procedure?», BYbIL, vol. 31, 1954, pp. 452-458. 
El fundamento del agotamiento de los recursos internos como norma de procedimiento reside en la función procesal previa que la norma desempeña para la hacer efectiva la ejecución, aunque no el nacimiento, de la responsabilidad internacional. Esta se originaría a partir del momento en que el hecho ilícito o daño causado se hubieran producido, aunque no se hubieran agotado previamente los recursos internos. Esta hipótesis la ha apoyado en el pasado una parte importante de la doctrina (Charles de Vischer ${ }^{45}$ o Gerald Fitzmaurice ${ }^{46}$ ), de la magistratura ${ }^{47}$ y el propio TIJ en el caso Barcelona Traction $^{48}$ y en el caso Elettronica Sicula ${ }^{49}$.

La interpretación del agotamiento de los recursos internos como norma de fondo o sustancia se fundamenta en que el «fatto illecito internazionale perfetto" y, por tanto, la responsabilidad internacional que de él se deriva, solo se genera después de haber agotado, con anterioridad y sin éxito, todos los recursos disponibles en el Derecho interno. Su valedor más importante ha sido Roberto Ago, quien dejó escrita su posición en los trabajos de la Comisión de Derecho Internacional (CDI) ${ }^{50}$. En la práctica internacional, esta hipótesis se apoya en el caso de la Mexican Union Railway resuelto por la Comisión Mixta de Reclamaciones Reino Unido/México ${ }^{51}$, en la posición de Polonia en el caso de la Administración del Príncipe von Pless ${ }^{52}$, en las opiniones disidentes o individuales de algunos magistrados del TPJI y del TIJ ${ }^{53}$, o en la propia Comisión Europea de Derechos Humanos, que ha afirmado que «la responsabilidad de un Estado con arreglo a la Convención de Derechos Humanos solo nace [...] a partir del momento en que se han agotado todos los medios de recurso internos» ${ }^{54}$.

La división existente en dos bandos teóricos y prácticos estancos sobre la naturaleza del agotamiento de los recursos internos ha generado dudas

45 Véase, sobre todo, DE VISSCHER, C., «Note sur la responsabilité international des Etats et la protection diplomatique, d'après quelques documents récents", Revue de droit international et de législation comparée, vol. 8, 1927, pp. 245 y ss.; y, del mismo autor, "Le dénie de justice en droit international», RCADI, vol. 52, 1935, pp. 369-441, esp. pp. 421 y ss.; y AmERASINGHe, C. F., "The Formal Character of the Rule of Local Remedies», ZaöRV, vol. 25, 1965, pp. 445-477.

${ }^{46}$ Fitzmaurice, G., «The Meaning of the Term Denial of Justice», BYbIL, vol. 13, 1932, pp. 93-114, esp. p. 96.

${ }^{47}$ La opinión individual del juez Tanaka en el caso de Barcelona Traction (Bélgica c. España), ICJ Reports 1970, p. 143.

48 Barcelona Traction (Bélgica c. España), ICJ Reports 1970, p. 46.

49 Barcelona Traction (Bélgica c. España), ICJ Reports 1970, párr. 59.

50 Ago, R., «La Regola del Previo Esaurimento dei Ricorsi Interni in Tema di Responsabilità Internazionale», Archivio di Diritto Pubblico, vol. 3, 1938, p. 182. Véase Anuario CDI, vol. II, 1977, 2. ${ }^{a}$ Parte, p. 37.

51 Recueil des sentences arbitrales, vol. V, p. 122.

52 Administración del Príncipe von Pless, CPJI, Serie C, núm. 70, pp. 134-135.

53 La opinión disidente del juez Hudson en Ferrocarril Panevezys-Saldutiskis, CPJI, 1939, Serie A/B, núm. 76, p. 47; la opinión individual del juez Córdova en Interhandel (Suiza c. Estados Unidos de América) (Excepciones preliminares), ICJ Reports 1959; y la opinión disidente del juez Morelli en el caso Barcelona Traction (Bélgica c. España), ICJ Reports 1964, p. 114.

54 Decisión de 10 de junio de 1958, núm. 235/56, Annuaire de la Convention européenne des droits de l'homme 1958-1959, vol. 2, p. 305. Véase D'ASCOLI, S. y SCHERR, K., "The Rule of Prior Exhaustion of Local Remedies in the International Law Doctrine and its Application in the Specific Context of Human Rights Protection», EUI Working Papers Law, 2007, p. 5. 
e incertidumbre en la práctica jurisprudencial ${ }^{55}$. A mi juicio, un atisbo de solución se podría encontrar si se reconoce que el fundamento del agotamiento de los recursos internos y la principal razón de su existencia residen en «la necesidad indispensable de armonizar las jurisdicciones nacional e internacional, asegurando de esta forma el respeto debido a la jurisdicción soberana de los Estados» ${ }^{56}$. Se trata, a mi juicio, de una norma de carácter mixto. Por una parte, funciona como condición para la admisibilidad de una demanda, como "una regla procesal que realiza un cierto equilibrio entre la soberanía del Estado demandado y las exigencias superiores del Derecho Internacional» ${ }^{57}$ (art. 35 del CEDH). Y, por otra parte, desempeña un papel fundamental como instrumento que garantiza el cumplimiento de derechos y obligaciones sustantivos, como lo demuestra la jurisprudencia del Tribunal Europeo de Derechos Humanos (TEDH) relativa al derecho de toda persona a la concesión de un recurso efectivo en caso de violación de sus derechos y libertades (art. 13 del CEDH) ${ }^{58}$.

15. También ha resultado polémica la jurisprudencia que otorga preeminencia a las normas que salvaguardan garantías procesales fundamentales sobre el fondo en el ámbito de la lucha contra el terrorismo internacional y, más específicamente, de los asuntos relativos al listado de personas sujetas a medidas restrictivas. En los asuntos Kadi, el Tribunal de Justicia de la UE (TJUE) ha establecido que «los Tribunales de la Unión deben garantizar un control en principio completo, de la legalidad de todos los actos [de la UE] desde el punto de vista de los derechos fundamentales que forman parte integrante de los principios generales del Derecho de la Unión, control que también se extiende a los actos [...] destinados a aplicar resoluciones aprobadas por el Consejo de Seguridad en virtud del Capítulo VII de la Carta de las Naciones Unidas». Estos derechos, reconocidos en la Carta de los Derechos Fundamentales de la UE incluyen, entre otros, el respeto al derecho de defensa (art. 41.2) y el derecho a la tutela judicial efectiva y a un juez imparcial (art. 47) ${ }^{59}$. Lo que convierte en excepcional esta jurisprudencia, es la consideración del TJUE de que las garantías procesales de la UE prevalecen incluso sobre las medidas relativas al mantenimiento de la paz y seguridad internacionales, contenidas en resoluciones vinculantes del Consejo de Seguridad de Naciones Unidas adoptadas con arreglo al art. 25 de la Carta de las Naciones Unidas (Carta) en un contexto donde los Estados miembros de la UE actúan en el marco de los Tratados de la UE («compétence liée», «mandatory rule») ${ }^{60}$.

55 Recueil des sentences arbitrales, vol. II, p. 1502; y Fosfatos de Marruecos, CPJI, 1938, Serie A/B, núm. 74, p. 28.

56 Véase la opinión individual del juez Córdova en Interhandel (Suiza c. Estados Unidos de América) (Excepciones preliminares), ICJ Reports 1959, p. 45.

57 DE VISSCHER, C., op. cit., nota 44, p. 423.

58 Akdivar y otros c. Turquía, núm. 21893/93, párr. 65, TEDH 1996.

59 Asuntos C-584/10-P, C-593/10-P y C-595/10-P, ECLI:EU:C:2013:518, párrs. 97, 99-100 y 102. Véanse igualmente los asuntos C-399/06-P y C-403/06-P, ECLI:EU:C:2009:748, párr. 71; y asunto C-548/09-P, ECLI:EU:C:2011:735, párr. 105.

${ }^{60}$ Asunto T-184/95, ECLI:EU:C:2000:321, párr. 74. 
Al justificar que las obligaciones de la Carta son requisitos dimanantes de un acuerdo internacional ordinario y que como tales tienen que conformarse a los derechos fundamentales de la UE, que tienen valor de derecho primario, la jurisprudencia del TJUE se aleja de la sabiduría tradicional que estima que la Carta no es un acuerdo internacional ordinario y que su aceptación universal y la cláusula de supremacía prevista en su art. 103, la convierte en la autoridad suprema del DI público y, para un número importante de internacionalistas, en una verdadera "constitución de la comunidad internacional» ${ }^{61}$. Además, el TJUE ha asumido el riesgo que, como muestra alguna práctica estatal, las cuestiones de procedimiento puedan servir de subterfugio para eludir el pronunciamiento sobre cuestiones de fondo relativas a violaciones de los derechos humanos.

En los Estados Unidos de América, tras los atentados del 11 de septiembre de 2001, los programas más controvertidos de la lucha contra el terrorismo se llevaron a cabo cometiendo violaciones significativas de los derechos humanos (tortura y otras formas de tratos crueles, encarcelamientos, deportaciones, violaciones de llamadas telefónicas privadas y de datos personales). Los procesos que se incoaron contra esas políticas raramente se basaron en reclamaciones sustanciales sobre las violaciones de esos derechos humanos sino que, en su mayor parte, se fundamentaron en cuestiones de procedimiento (entre otras, cuestiones de jurisdicción y competencia de los tribunales, cuestiones de distribución de poderes entre el poder legislativo y el ejecutivo, cuestiones de legitimación y cuestiones de prueba) ${ }^{62}$, lo que ha llevado a los propios analistas americanos a concluir que había habido «mucho procedimento pero poca justicia» ${ }^{63}$.

16. Finalmente, se observa un vínculo conceptual entre fondo y forma en el ámbito de la protección internacional del medio ambiente y, en particular, del principio de prevención de un daño ambiental transfronterizo significativo. Este principio forma parte del DI consuetudinario y hunde sus orígenes en la debida diligencia que se requiere del Estado en su territorio.

Para cumplir con la obligación de ejercer la debida diligencia un Estado debe, antes de embarcarse en una actividad que tenga el potencial de afectar

61 Chemain, R. y Pellet, A. (eds.), La Charte des Nations Unies, constitution mondiale?, París, Pedone, 2006. La tesis del TJUE en el asunto Kadi ha sido descrita como «Unfaithfull to its traditional fidelity to public international law» (DE BÚRCA, G., «The European Court of Justice and the International Legal Order After Kadi», Harvard ILJ, vol. 51, 2010, pp. 1-49, esp. pp. 44 y ss.), y como giro a la tesis dualista (FAssBender, B., "Triepel in Luxembourg. Die dualistische Sicht des Verhältnisses zwischen Europa - und Völkerrecht in der "Kadi-Rechtsprechung" des EuGH als Problem des Selbstverständnisses der Europaischen Union», Die Öffentliche Verwaltung, 2010, p. 340). Aunque confirma su "fe misionera» en defensa de los derechos humanos [MANGaS MARTín, A., "Evolución del respeto a los derechos humanos en la Unión Europea (teoría y práctica ante los nuevos desafíos del terrorismo)», Agenda Internacional, 2008, núm. 26, p. 25].

${ }^{62}$ Rasul v. Bush, 542 U.S. 466, 485 (2004); Rumsfeld v. Padilla, 542 U.S. 426, 446 (2004); Hamdan v. Rumsfeld, 126 S.Ct. 2749, 2797 (2006); Hamdi v. Rumsfeld, 542 U.S. 507, 533 (2004); y ACLU v. NSA, 493 F.3d 644, 687 (6th Cir. 2007 cert. denegado, 128 S. Ct. 1334 (2008)).

${ }^{63}$ "Unfortunately, the "war on terror" litigation thus far seems to have resulted in a great deal of process, and not much justice»: véase MARTínez, J. S., "Process and Substance in the "War on Terror"», Columbia Law Review, vol. 108, 2008, núm. 5, pp. 1013-1092, esp. p. 1092. 
adversamente el medio ambiente de otro Estado, llevar a cabo un estudio de impacto ambiental para averiguar si existe un riesgo de un daño transfronterizo significativo ${ }^{64}$. Si el estudio de impacto ambiental confirma que existe un riesgo de un daño transfronterizo significativo, el Estado que planea llevar a cabo la actividad debe, de conformidad con su obligación de debida diligencia, notificar y consultar en buena fe a los Estados potencialmente afectados, cuando esto sea necesario para determinar las medidas apropiadas para prevenir o mitigar ese riesgo.

Aunque el TIJ no reconoce explícitamente que existe una violación de la obligación sustancial de la prevención del daño cuando un Estado no cumple con la diligencia debida, por no llevar a cabo un estudio de impacto ambiental y no se ha producido un daño transfronterizo significativo ${ }^{65}$, el Tribunal Internacional del Derecho del Mar (TIDM) ha reconocido explícitamente que la debida diligencia constituye el vínculo conceptual, a la vez formal y sustancial, entre la prevención del daño y la precaución ${ }^{66}$.

\subsection{Sobre la inutilidad e inconveniencia de establecer criterios estancos en la distinción entre fondo y forma}

17. El análisis llevado a cabo demuestra que la realización del Estado de Derecho internacional requiere gran permeabilidad/flexibilidad en el tratamiento de las cuestiones de fondo y de forma, lo que induce a formular las reflexiones siguientes.

18. En primer lugar, algunas cuestiones pueden ser tratadas indistintamente como de fondo o de forma. Me refiero a la cuestión de la jurisdicción. La jurisdicción constituye una característica de la soberanía, cuestión de fondo, y se manifiesta en el ejercicio de la capacidad/autoridad internacional de carácter general (giurisdizione, compétence générale) para crear, modificar o terminar relaciones y obligaciones jurídicas por medio de una acción legislativa, ejecutiva o judicial. En cambio, la jurisdicción se convierte en una cuestión de forma cuando se trata como una cuestión de competencia, es decir, la facultad que se le da a un tribunal para determinar la forma objetiva (determinada por la materia), funcional (distintos grados de organismos judiciales) y territorial (espacio que corresponde a un juzgado) donde se ejerce la administración de justicia. En ciertos ordenamientos jurídicos, algunas cuestiones jurisdiccionales son tratadas como procesales: por ejemplo la Regla 12(h)(3) de las Federal Rules of Civil Procedure de los Estados Unidos de América trata

${ }^{64}$ Canal de Corfú (Reino Unido c. Albania), ICJ Reports 1949, p. 22; y Plantas de celulosa en el río Uruguay (Argentina c. Uruguay), ICJ Reports 2010, párrs. 101 y 204.

${ }_{65}$ Ciertas actividades llevadas a cabo por Nicaragua en la zona fronteriza (Costa Rica c. Nicaragua) y Construcción de una carretera en Costa Rica a lo largo del río San Juan (Nicaragua c. Costa Rica) (Procedimientos acumulados), ICJ Reports 2015, párrs. 104 y ss.

${ }^{66}$ Aspectos relativos a la determinación del vínculo efectivo entre los Estados y las personas jurídicas a las que patrocinan para llevar a cabo actividades en la Zona, opinión consultiva, ITLOS Reports 2011, p. 34 . 
como procesal la cuestión de la ausencia de jurisdicción del tribunal sobre la cuestión de fondo ${ }^{67}$.

No parece aceptable la tradicional reticencia del TIJ a entrar en el fondo de las cuestiones relativas al desarme o las armas nucleares, tal vez por considerarlas «políticas» o proclives natura sua a ser resueltas mediante procesos políticos: es evidente que estos procesos, a pesar de los años transcurridos, no las han resuelto ${ }^{68}$ y también resulta obvio que el recurso a un rígido formalismo afecta al cumplimiento de normas sustanciales que conciernen a la comunidad internacional en su conjunto. Estas consecuencias demuestran no solo la necesidad de moldear el resultado a través de la función interpretativa del TIJ, sino la obligación de buscar/establecer mecanismos (judiciales o no) alternativos de resolución de las controversias de esta naturaleza ${ }^{69}$. En el caso del África Sudoccidental, el TIJ reconoció que la protección judicial era una parte esencial del mandato de la ONU sobre Sudáfrica y que este principio operaba como condición esencial de confianza y garantía de derechos de los Estados miembros de la ONU cuando se trataba de los mandatos de esta organización ${ }^{70}$, lo que acarrea dos consecuencias. Primera, existen ciertos casos donde los Estados reconocen que la protección judicial es necesaria. Y, segunda, los Estados pueden tener derecho al acceso a la justicia y a la tutela judicial, incluso cuando no hubo una conducta dañosa por parte de otro Estado.

Por tanto, si una actio popularis resultara descartable en la actualidad ${ }^{71}$, se podría recurrir a la creación de mecanismos que se inspirasen en el Estatuto del Tribunal Penal Internacional o en el Entendimiento relativo a las normas y procedimientos por los que se rige la solución de diferencias de la OMC (ambos instrumentos contienen disposiciones que remiten a un órgano político, respectivamente la Asamblea de los Estados Partes y el Órgano de Solución de Diferencias). Finalmente, por muy difícil que se presente, tampoco debería ser descartado, per se, el recurso a la modificación de los arts. 3436 del Estatuto del TIJ (jurisdicción voluntaria, locus standi y competencia ratione materiae).

${ }^{67}$ Este precepto dispone que: «Lack of Subject-Matter Jurisdiction. If the court determines at any time that it lacks subject-matter jurisdiction, the court must dismiss the action".

68 Ranganathan, S., "Nuclear Weapons and the Court», AJIL Unbound, vol. 111, 2017, pp. 88-95, esp. p. 88.

69 ProulX, V., «The Marshall Islands Judgments and Multilateral Disputes at the World Court: Wither Access to International Justice?», AJIL Unbound, vol. 111, 2017, pp. 96-101. En este artículo se propone la combinación de la utilización de las funciones de arreglo de controversias previstas en el Capítulo VI de la Carta para el Consejo de Seguridad y el art. 27.3 de la Carta, según el cual «en las decisiones tomadas en virtud del Capítulo VI [...] la parte en una controversia se abstendrá de votar».

${ }^{70}$ África Sudoccidental (Liberia c. África del Sur) (Etiopía c. África del Sur) (Excepciones Preliminares), ICJ Reports 1962, p. 337.

${ }^{71}$ África Sudoccidental (Liberia c. África del Sur) (Etiopía c. África del Sur) (Segunda Fase), ICJ Reports 1966, p. 487, el TIJ decidió que la actio popularis «no está reconocida por el Derecho internacional en su estado actual [...] ni el tribunal está capacitado para reconocerla como parte de los principios generales del Derecho»: véase VoEfFray, F., L'actio popularis ou la défense de l'intérêt collectif devant les juridictions internationales, Ginebra, Graduate Institute, 2004, pp. 324-382. 
19. En segundo lugar, también requiere flexibilidad conceptual la aplicación de la distinción entre fondo y forma a la resolución de las cuestiones relativas a la jurisdicción, la responsabilidad y la reparación. Por una parte, aunque la jurisprudencia del TIJ en el caso de las Inmunidades jurisdiccionales del Estado parece inclinarse hacia el establecimiento de categorías absolutas al afirmar que «la cuestión de saber si un Estado puede gozar de la inmunidad frente a las jurisdicciones de otro Estado es completamente distinta de aquella de saber si la responsabilidad internacional de este Estado está comprometida y si ello acarrea una obligación de reparación» ${ }^{72}$, la propia jurisprudencia descarta tal radicalidad distintiva en el marco de la adopción de medidas provisionales. En efecto, incluso cuando el TIJ duda sobre la existencia de competencia "para ocuparse del fondo del asunto», el objetivo primordial de la facultad que se le reconoce de indicar la adopción de medidas provisionales «es proteger los derechos respectivos de las partes en espera de un fallo del TIJ, y presupone que no se causará ningún perjuicio irreparable a los derechos que sean objeto de una controversia en actuaciones judiciales» ${ }^{73}$.

Por otra parte, aunque los textos legislativos parecen establecer que la reparación se ajusta más a una regla de fondo que de forma ${ }^{74}$, la jurisprudencia del TIJ ${ }^{75}$ y del TEDH ${ }^{76}$ establece estrechos vínculos entre la sustancia de los principios de la reparación y los procedimientos que se aplican para hacer efectiva dicha reparación. Asimismo, como ha quedado demostrado en las páginas precedentes, se comparten aspectos procesales y sustanciales cuando la admisibilidad de la reclamación y, por tanto, la invocación de la responsabilidad, está sujeta a la norma del agotamiento de los recursos internos y no se han agotado todas las vías de recurso internas disponibles y efectivas ${ }^{77}$.

Finalmente, los estrechos vínculos entre fondo y forma se ponen de manifiesto en la resolución de cuestiones relativas a la responsabilidad conjunta y solidaria de los Estados (joint and several liability). Por ejemplo, cuando dos o más Estados lanzan conjuntamente un objeto espacial en aplicación de los

72 Inmunidades Jurisdiccionales del Estado (Alemania c. Italia: Grecia interviniente), ICJ Reports 2012, párr. 100; y Orden de detención (República Democrática del Congo c. Bélgica), ICJ Reports 2002, párr. 60 .

${ }^{73}$ Convención de Viena sobre relaciones consulares (Paraguay c. Estados Unidos de América), ICJ Reports 1998; y Proyecto Gabcíkovo-Nagymaros (Hungría/Eslovaquia), ICJ Reports 1997.

74 El art. 31 de los Proyectos de artículos sobre la responsabilidad del Estado y de las organizaciones internacionales por hechos internacionalmente ilícitos formula la reparación generalmente en términos sustanciales, al disponer que «el Estado responsable está obligado a reparar íntegramente el perjuicio causado por el hecho internacionalmente ilícito [...]. El perjuicio comprende todo daño, tanto material como moral, causado por el hecho internacionalmente ilícito del Estado».

75 Convención de Viena sobre relaciones consulares (Paraguay c. Estados Unidos de América), ICJ Reports 1998; y Proyecto Gabcíkovo-Nagymaros (Hungría/Eslovaquia), ICJ Reports 1997. Véase GRAY, C., «The Choice between Restitution and Compensation», EJIL, vol. 10, 1999, pp. 422-423.

76 Pellonpä̈, M., "Individual reparation claims under the European Convention on Human Rights», en Tomuschat, Ch. y Radelzhofer, A. (coords.), State responsibility and the individual: reparation in instances of grave violations of human rights, Leiden, Martinus Nijhoff, 1999, pp. 109-130.

77 Arts. 44.b) y 45 del Proyecto de artículos sobre la responsabilidad del Estado por hechos internacionalmente ilícitos. 
arts. 5 y 15 del Convenio sobre la responsabilidad internacional por daños causados por objetos espaciales; cuando dos o más Estados participan en una empresa comercial conjunta (commercial joint venture) que causa daño medioambiental a un tercer Estado o cuando varios Estados violan de forma separada una obligación en relación con un mismo acontecimiento ${ }^{78}$. Para hacer frente a las dificultades procesales, el DI público ha encontrado soluciones de diverso tipo, incluso de naturaleza sustancial, como el Derecho del Estado que haya pagado la indemnización por daños a recuperar judicialmente la parte correspondiente atribuible a los demás Estados participantes ${ }^{79} \mathrm{o}$ la posibilidad de concertar acuerdos acerca de la distribución entre los Estados de la carga financiera respecto de la cual son solidariamente responsables, prevista en el art. 5 del Convenio precitado.

20. En tercer lugar, existen supuestos en los que el desarrollo del Derecho sustantivo puede afectar la interpretación de las normas de la intervención procesal, y viceversa. Por una parte, el procedimiento puede constituir efectivamente «un instrumento de poder que puede, en su aplicación práctica, generar o socavar los derechos sustantivos» ${ }^{80}$. En el ámbito del DI penal, el procedimiento no tiene únicamente la finalidad instrumental de aplicar las leyes de fondo, sino que ejecuta sus propios valores sustanciales al reivindicar el Estado de Derecho ${ }^{81}$. Por otra parte, la justicia (fairness), en su vertiente sustancial (la justicia distributiva), y el procedimiento (due process o proceso correcto) pueden perseguir un fin distinto cuando el objetivo de la primera es el cambio, mientras que el del segundo es el orden y la estabilidad. La resolución defectuosa de esta dicotomía en la jurisprudencia del TIJ (reconocimiento del principio erga omnes, pero ausencia de establecimiento de un mecanismo para hacerlo cumplir) ${ }^{82}$ ha originado una tensión «entre la estabilidad y el cambio (que) puede desestabilizar un ordenamiento jurídico si no se controla a través de la rúbrica de la justicia» ${ }^{83}$.

21. En cuarto lugar, se estima que una concepción puramente instrumentalista del procedimiento, como mero transmisor del fondo, limitado a

78 Noyes, J. y Smith, B., «State Responsibility and the Principle of Joint and Several Liability», The Yale Journal of International Law, vol. 13, 1988, núm. 2, pp. 225-267.

79 Aspectos relativos a la determinación del vínculo efectivo entre los Estados y las personas jurídicas a las que patrocinan para llevar a cabo actividades en la Zona, opinión consultiva, ITLOS Reports 2011, p. 34 .

80 MaIn, Th., «The Procedural Foundation of Substantive Law», Washington University Law Rev., vol. 87, 2010, núm. 4, pp. 801-841, esp. p. 802.

81 OHLIN, J., "Meta-Theory of International Criminal Procedure: Vindicating the Rule of Law», UCLA Journal of International Law and Foreign Affairs, vol. 14, 2010, pp. 77-120. Véanse al respecto los Principios y reglas generales de procedimiento penal internacional (Amsterdam Center for International Law of the University of Amsterdam y Hague Institute for the Internationalization of Law, 2011).

${ }^{82}$ Barcelona Traction (Bélgica c. España), ICJ Reports 1970, párr. 31. Véanse igualmente Timor Oriental (Portugal c. Australia), ICJ Reports 1995, p. 90; Aplicación de la Convención para la prevención y la sanción del delito de genocidio (Bosnia y Herzegovina c. Serbia y Montenegro) (Medidas provisionales), ICJ Reports 1993, p. 325; y el laudo arbitral dictado en el caso de la Delimitación de los espacios marítimos entre Canadá y la República Francesa (ILM, vol. 31, 1992, p. 1145, párrs. 78-79).

83 FrancK, Th., Fairness in International Law and Institutions, Oxford, Clarendon Press, 1997, p. 7. 
una función de lo que Jeremy Bentham denominó como «derecho adjetivo», y cuya única finalidad sería la de «llevar a cabo la voluntad manifestada en el cuerpo del derecho sustantivo» ${ }^{84}$, abriría la posibilidad de obtener una interpretación de las normas sobre la legitimación (locus standi) y la intervención procesal que fuera transmisora de los intereses sustanciales de la comunidad internacional en su conjunto, en particular en los asuntos donde las obligaciones erga omnes y de jus cogens forman parte de la controversia $^{85}$. En el caso de las Actividades armadas en el territorio del Congo, el TIJ se mostró abierto a esta posibilidad al justificar la necesidad de proteger los derechos humanos y el DI humanitario como fundamento del establecimiento de medidas provisionales con carácter de urgencia ${ }^{86}$.

A mi juicio, una concepción puramente instrumentalista del procedimiento no resulta plenamente satisfactoria por tres razones. Primera, el contenido del jus cogens no está predeterminado, su ámbito no es ilimitado y, por tanto, existe el riesgo de que ese concepto pueda ser utilizado para socavar principios procesales aceptados y aplicados sistemáticamente por los Estados y la opinio juris internacional. Segunda, no existe una norma de carácter imperativo que requiera a los Estados someterse a la jurisdicción internacional del TIJ en los supuestos donde el cumplimiento de una norma de jus cogens forma parte de la controversia (solamente los Estados pueden modificar el art. 36 del Estatuto del TIJ) ${ }^{87}$. Y, tercera, la concepción instrumentalista no ofrece ningún criterio para determinar la elección de los valores sustanciales que las reglas de procedimiento deben aplicar en los casos donde exista una discrepancia entre dos valores fundamentales, por ejemplo, la protección de los derechos humanos y del medio ambiente $^{88}$.

22. En quinto lugar, una variante de la hipótesis instrumentalista sería concebir el procedimiento como método doctrinal formal, analítico y resolutorio de las cuestiones de fondo. En particular, ciertos sectores de la doctrina han propuesto la utilización de dicho método para adaptar a la realidad actual el estricto y restrictivo régimen convencional relativo a la prohibición del uso de la fuerza y sus excepciones previsto en los arts. 2 y 24-25 de la Carta ${ }^{89}$. El método de la «forma doctrinal» se ha propuesto para resolver la falta de seguridad jurídica existente sobre cuestiones como la legitimidad de la defensa preventiva, la legalidad de una autorización implícita del Consejo de

\footnotetext{
${ }^{84}$ Bentham, J., "Principles of Judicial Procedure with the Outlines of a Procedural Code», en Bowring, J., The Works of Jeremy Bentham, Edimburgo, vol. 2, William Tait, 1843, p. 6.

85 NollKaemper, A., "International Adjudication of Global Public Goods: the Intersection of Substance and Procedure», EJIL, vol. 23, 2012, núm. 3, pp. 769-791, esp. pp. 769 y 781.

${ }^{86}$ Actividades armadas en el territorio del Congo (República Democrática del Congo c. Uganda) (Medidas Provisionales), ICJ Reports 2000, p. 128, párr. 43.

87 Véase la opinión separada del juez ad hoc Dugard en el caso de las Actividades armadas sobre el territorio del Congo (República Democrática del Congo c. Ruanda), ICJ Reports 2006, párrs. 2-3, 6 y 13.

${ }^{88}$ NollKaemper, A., op . cit., nota 84.

89 WaXman, M., "Regulating Resort to Force: Form and Substance of the UN Charter Regime», EJIL, vol. 24, 2013, núm. 1, pp. 151-189.
} 
Seguridad o el derecho de intervención humanitaria ${ }^{90}$. Al quedar descartada por incorrecta la jurisprudencia fundamentada en una actualización del DI humanitario de origen consuetudinario basada exclusivamente en la existencia de una opinio juris ${ }^{91}$, se sugiere la utilización de un método de argumentación y análisis centrado en «la valoración de los hechos puestos en relación con las normas jurídicas» ${ }^{92}$. Según sus proponentes, este método permitiría el establecimiento de cánones y puntos de referencia interpretativos flexibles y discrecionales que neutralizarían cuestiones controvertidas sobre la insuficiencia o validez de las herramientas de que dispone el DI público en el ámbito del uso de la fuerza y abriría las puertas a una nueva manera de concebir su reforma legal ${ }^{93}$.

A mi juicio, se trata una propuesta artificial e inconcreta que se basa en postulados que no tienen en cuenta la existencia de zonas grises ni valoran las ventajas que ofrece el análisis de la interpretación basada en las posiciones expresadas por la mayoría de los Estados y la doctrina internacional ${ }^{94}$. Finalmente, la práctica internacional en el marco del Entendimiento relativo a las normas y procedimientos por los que se rige la solución de diferencias de la OMC demuestra que existen cauces a través de las reglas relativas a la admisibilidad, la intervención o los amici curiae, que permiten obtener soluciones equilibradas en cuanto al fondo y que resultan mucho mas fructíferas ${ }^{95}$.

23. En sexto lugar, el Derecho sustantivo, el fondo, no es nunca «a-procedimental». Por ejemplo, el DI penal o la protección de los derechos humanos, siempre se interpretan y aplican, consciente o inconscientemente, teniendo en mente un procedimiento que reivindica los derechos que amparan y que determina las responsabilidades que de su incumplimiento se derivan ${ }^{96}$. En otros ámbitos se puede hablar de un «fundamento formal del fondo» (un

90 Existe gran controversia sobre esta cuestión: véanse GrAY, C., International Law and the Use of Force, 4. ${ }^{\text {a }}$ ed., Oxford, Oxford University Press, 2018; y FranK, T., Recourse to Force. State Actions Against Threats and Armed Attacks, Cambridge, Cambridge University Press, 2002.

91 Véase Prosecutor c. Kupreškić y otros, IT-95-16-T, párr. 527, donde la Sala de Primera Instancia del Tribunal Internacional para la ex Yugoslavia afirmó que «los principios de Derecho internacional humanitario pueden surgir por conducto de un proceso consuetudinario bajo la presión de las exigencias de la humanidad o los dictados de la conciencia pública, aun cuando la práctica de los Estados sea escasa o incoherente. El otro elemento, en la forma de opinio necessitatis, cristalizado a resultas de los imperativos de humanidad o la conciencia pública, puede convertirse en el elemento decisivo que indique el surgimiento de una norma o un principio general del Derecho humanitario».

92 WAXMAN, M., op. cit., nota 88.

93 Waxman, M., «Regulating Resort to Force: A Response and Thanks to Corten», EJIL:Talk de 2 de mayo de 2013.

94 CORTEN, O., «Regulating Resort to Force: A Response to Matthew Waxman from a Bright-Liner», EJIL, vol. 24, 2013, núm. 1, pp. 191-197.

95 La aplicación práctica del Acuerdo sobre los Aspectos de los Derechos de Propiedad Intelectual relacionados con el Comercio y, en particular, de la protección mediante patente de las invenciones en la esfera de los productos farmacéuticos, ha establecido un equilibrio entre los intereses de los titulares de los derechos y los de los usuarios. Véase el Laudo arbitral sobre la Reclamación presentada por las Comunidades Europeas y sus Estados miembros contra Canadá el 19 de diciembre de 1997 y la Sentencia del TJUE en el asunto C-414/11, ECLI:EU:C:2013:520.

${ }^{96}$ MaIN, Th., op. cit., nota 79, p. 822. 
"procedural foundation of substantive law») como, por ejemplo, cuando se presentan ante los tribunales internos reclamaciones donde los daños sustanciales se determinan con arreglo al DI público, mientras que las cuestiones de procedimiento se rigen por la lex for $i^{97}$.

24. En conclusión, la práctica internacional demuestra que en DI público no resulta útil o convincente el establecimiento de una distinción entre fondo y forma fundamentada en criterios rígidos o estancos, como la remisión sistemática a la forma de todas las cuestiones relativas al funcionamiento interno del tribunal de justicia o al gobierno del proceso del litigio, mientras que todas las demás cuestiones externas al proceso del litigio formarían parte del fondo ${ }^{98}$; o instaurando clasificaciones sofisticadas que obedezcan a precisiones inoperantes de los términos "proceso» $\mathrm{y}$ "procedimiento» ${ }^{99} \mathrm{O}$, en general, estableciendo distinciones binarias estrictas.

A efectos de la resolución de las cuestiones de fondo y forma, no resulta operativa ni viable la construcción de una teoría basada en unos supuestos principios generales de DI procesal de aplicación estricta, de los que se derivarían reglas de procedimiento detalladas secundarias de aplicación flexible. Tampoco pueden ser reducidas a meras cuestiones de procedimiento cuestiones que, como los plazos, se presentan en el sistema internacional de solución de diferencias. De la misma forma que no es exclusivamente sustancial la cuestión del derecho de verter mercurio en los cursos de agua internacionales.

El procedimiento, la forma, no solamente es transmisor de la sustancia o es protector de derechos procesales intrínsecos (garantías y derechos fundamentales), sino que es codeterminante de lo que es el propio Derecho antes que nada ${ }^{100}$. Al mismo tiempo, el fondo nunca es «a-procedimental»: todo es fondo cuando el procedimiento determina la solución de un litigio particular; a la inversa, todo es forma cuando el Derecho sustantivo aparece condicionado por los métodos por los que las reclamaciones jurídicas se inician o se solucionan. Aunque la función primordial de los tribunales es proteger los

\footnotetext{
97 Ibid., p. 816.

98 Este modo de diferenciar fondo y forma fue defendido por SALMOND, J., Jurisprudence: or the Theory of Law, Londres, Stevens and Haynes, 1902, pp. 577-578.

$99 \mathrm{El}$ «proceso judicial» incluiría el conjunto de actos jurídicos que se llevan a cabo para aplicar la ley a la resolución de un caso (entre otros, desarrollo de la función jurisdiccional, tutela judicial efectiva, derecho de acción) y que incluye el juicio, la acción de juzgar (incluida la jurisdicción voluntaria) y el medio empleado para ello. Mientras que el "procedimiento» consiste en el conjunto de normas jurídicas generales para llevar a cabo el juicio y que regulan los trámites, actos y resoluciones a través de los cuales los jueces y tribunales ejercitan su potestad jurisdiccional, juzgando y haciendo ejecutar lo juzgado en el proceso. Véanse Kolb, R., «General Principles of Procedural Law», en ZimmermanN, A., Tomuschat Ch. y Oellers-Frahm, K. (eds.), The Statute of the International Court of Justice: A Commentary, Oxford, Oxford University Press, 2006, pp. 871-908. Asimismo, confrontar con RosenNE, S.,

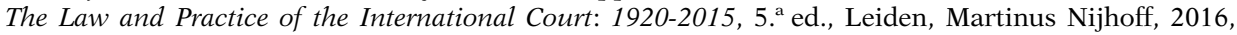
párr. 254; GuYomar, G., Commentaire du Règlement de la Cour internationale de Justice, adopté le 17

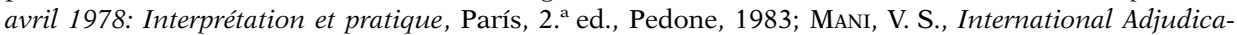
tion. Procedural Aspects, Leiden, Martinus Nijhoff, 1980; 1973; y DEL VecchIO, A., Le parti nel processo internazionale, Milán, Giuffré, 1975.

100 NollKaemper, A., op. cit., nota 84, p. 785.
} 
derechos procesales inherentes a sistema internacional de solución de controversias, resulta inaceptable recurrir al procedimiento para evitar o retrasar la aplicación del Derecho material. Incumbe a los legisladores y a la función judicial de los tribunales internacionales, que es esencialmente «un ejercicio de elección» ${ }^{101}$, moldear y desarrollar la interconexión entre fondo y forma.

\section{EL DECLIVE DE LA NORMA LEX FORI REGIT PROCESSUM}

25. En términos generales, el DI privado no tiene un contenido sustantivo/material, se trata de una técnica que no ofrece una solución inmediata a una disputa sino que opera indirectamente ${ }^{102}$ : determina el sistema jurídico que proporciona una ley aplicable para resolver la disputa. Precisamente por tratarse de una técnica, el DI privado ha sido históricamente sensible a la influencia extranjera y ha considerado importante la distinción entre fondo y forma en los ámbitos de la calificación (la aplicación de la ley extranjera); en el ámbito del arbitraje internacional (porque el proceso arbitral es independiente del sistema jurídico que regula los derechos y las obligaciones de las partes en relación con el acuerdo sustancial) o en el ámbito de las reclamaciones internacionales de responsabilidad contractual y extracontractual.

Como en DI público, también el DI privado ha conocido tentativas de establecer una distinción atendiendo al establecimiento de compartimientos estancos. Algunos autores estiman que esta debería circunscribirse al aspecto intelectual y material de la operación ${ }^{103}$. Los elementos que, en el acto jurídico, contribuyen a fijar la intención de las partes (consentimiento, capacidad, objeto y causa) constituirían elementos de fondo, como serían también todos los elementos que traducen la organización social en la que la ley se inserta obligatoriamente, como el matrimonio y el divorcio. En cambio, los elementos que, sin afectar a los objetivos privados o sociales, fijan los medios para manifestarlos con mayor certeza, pertenecerían a la forma ${ }^{104}$. En la misma línea, otros autores estiman que se debería centrar la distinción en las formas extrínsecas, es decir, las cumplimentadas por los interesados. De ahí que se excluya de su ámbito las formas habilitantes (cuyo objeto es la validez del acto en cuanto al fondo) y las de publicidad (cuya finalidad es la protección de terceros) y que solo se incluyan las formas solemnes y las de prueba ${ }^{105}$.

101 Véase la opinión individual del juez ad hoc Dugard en el caso de las Actividades armadas sobre el territorio del Congo (República Democrática del Congo c. Ruanda), ICJ Reports 2006, párr. 10; y la opinión consultiva sobre la Interpretación del Acuerdo de 25 de marzo de 1951 entre la OMS y Egipto, ICJ Reports 1980, p. 76.

102 Lipstein, K., Principles of the Conflict of Laws. National and International, La Haya, Springer, 1981, p. 2.

${ }^{103}$ LuIs-Lucas, P., «La distinction du fond et de la forme dans le règlement des conflits de lois», en Mélanges offerts à Jacques Maury, vol. I, París, Dalloz, 1961, p. 192.

104 Iglesias Buhigues, J. L., "La forma de los actos en el Derecho internacional Privado español», Documentación jurídica, vol. 24, 1979, p. 874.

105 Ibid., p. 875 y nota 4 al pie de la página donde cita en este sentido escritos de François Rigaux, Philippe Malaurie y Mariano Aguilar Navarro. 
En la actualidad, todas estas tentativas se han revelado insuficientes y de poca utilidad pues se fundamentan en un sustrato histórico, ya superado, que se remite a las teorías estatutarias elaboradas por las universidades italianas del siglo XIII. El Derecho de las ciudades-estado italianas (Génova, Pisa, Milán, Bolonia, Venecia, Florencia, Parma, Siena, Amalfi, entre otras) estaba incluido en «estatutos» que comprendían una amalgama de las actualizaciones declarativas de las viejas costumbres de la ciudad, de sus comunidades comerciales y de las nuevas normas jurídicas. La necesidad de establecer intercambios comerciales entre las distintas ciudades italianas y entre estas y Siria, Arabia, España y el sur de Francia, exigió la elaboración de normas que determinaran la elección del sistema jurídico aplicable. Inicialmente, tribunales y jueces aplicaban sistemáticamente el derecho de su propia ciudad, una práctica que se fundamentó en la idea de que las partes, al elegir el tribunal para resolver sus litigios, implícitamente seleccionaban el sistema jurídico del tribunal. Así, Iacobus Balduinus formula la siguiente declaración «iudicem illum eligendo videntur eligere statute et consuetudines suas» ${ }^{106}$.

La cuestión de la posibilidad de aplicar un Derecho extranjero la plantearon los glosadores y, en particular, Aldricus a finales del siglo XII quien estimó que cuando se planteaban cuestiones con elementos extranjeros, un juez debe aplicar el mejor Derecho o el más útil («debet enim iudicare secundum quod meius et visum fuerit») ${ }^{107}$. A principios del siglo XIII, se formuló por primera vez el principio de que las leyes de una ciudad o impuestas por un príncipe solo vinculan a los súbditos de ese príncipe o ciudad («Imperator non imposuit legem nisi suis subditis. Subditos tantum ligat consuetudo cuisqui civitatis») ${ }^{108}$. En el mismo periodo, Balduinus estableció la distinción más importante del DI privado, aquella relativa a la diferencia entre el derecho material o sustantivo (consuetudo ad litem decidendam) y el derecho del procedimiento (consuetudo ad litis ordinationem introducta). Las cuestiones de procedimiento se resolvían aplicando la ley del foro, mientras que las cuestiones de fondo o sustancia se decidían aplicando la ley del lugar $u b i$ contractum est ${ }^{109}$.

La distinción, que al principio no fue aceptada por muchos juristas italianos, sí fue integrada por juristas franceses de prestigio como Jacques de Révigny (1296) y Pierre de Belleperche (1308), quienes contribuyeron decisivamente a que finalmente fuera aceptada en Italia. De esta forma, nació la regla locus regit actum, fórmula latina inventada por los postglosadores, según la cual un acto jurídico está sometido a las condiciones jurídicas previstas por la ley del lugar donde el acto se ha celebrado. Destinada a ser adoptada en todo el mundo, el ámbito de aplicación de la regla locus regit actum no se

\footnotetext{
106 Wolf, M., Private International Law, Oxford, Clarendon Press, 1950, p. 22.

107 Gutzwiller, M., «Le développement historique du droit international privé», RCADI, vol. 29, 1929, pp. 291-394, esp. p. 301.

108 MeIJers, E., "Histoire des principes fondamentaux du droit international privé», RCADI, vol. 49, 1934, pp. 547-683, esp. pp. 592 y ss.

109 GutzWILler, M., op. cit., nota 106, p. 304.
} 
circunscribía originariamente a las cuestiones de forma, como ocurre hoy en día, sino que también se aplicaba a las condiciones de fondo relativas a la validez y los efectos de cualquier acto jurídico.

La regla locus regit formam actus, el Derecho del foro gobierna el procedimiento, que restringe el ámbito de aplicación de la locus regit actum a cuestiones de forma, es de origen francés, pues parece haber sido formulada por el francés Guillaume de Cun $^{110}$ y aplicada ya en el siglo XIII por el Parlament de Paris en los casos donde el demandado alegaba una costumbre extranjera como oponible para la no comparecencia ante un tribunal francés, alegación que era rechazada por ser una cuestión de procedimiento gobernada exclusivamente por el Derecho del foro ${ }^{111}$.

Así pues, tradicionalmente, la regla lex fori regit processum requiere que los tribunales del foro apliquen sistemáticamente sus reglas procesales en la resolución de los litigios que se les presentan y se sitúa, por tanto, fuera del ámbito de aplicación la norma de conflicto bilateral (choice of law) ${ }^{112}$. ¿Es eso cierto en la actualidad?

\subsection{La crisis de la distinción entre consuetudo ad litem decidendam y consuetudo ad litis ordinationem introducta}

26. En los sistemas de Derecho civil, la lex fori regit processum pasó a ser universalmente aceptada hasta prácticamente la actualidad. El art. 3 de la Ley de Enjuiciamiento Civil (LEC) española establece que, salvo lo dispuesto en los tratados y convenios internacionales, «los procesos civiles que se sigan en el territorio nacional se regirán únicamente por las normas procesales españolas». El Derecho italiano y francés contienen disposiciones en el mismo sentido $^{113}$. Su justificación radica en que se trata de una manifestación del principio del ámbito territorial de las normas procesales por ser estatales los órganos que la imparten ${ }^{114} \mathrm{y}$ por formar parte del Derecho público relativo a la administración de justicia ${ }^{115}$ (doctrina italiana y francesa) ${ }^{116}$.

Esta justificación ha sido criticada por toda una serie de razones. En primer lugar, no tiene en cuenta los intereses de las partes en el litigio, que al fin y al cabo son los actores principales en el procedimiento y que puede que

\footnotetext{
110 MeIJERs, E., op. cit., nota 107, p. 600.

111 AILES, E., «Substance and Procedure in the Conflict of Laws», Michigan Law Rev., vol. 39, 1941, pp. 392-418.

112 Véase en general ReQuejo IsIdRo, M., La ley local y forma de los actos en el Derecho internacional privado español, Madrid, Eurolex, 1998; SPIRo, E., «Forum regit processum», ICLQ, vol. 18, 1969, núm. 4, pp. 949-960, esp. pp. 949-950; y Harding v. Wealands (2007) 2 AC 1.

113 Véase, por ejemplo, la italiana Lege 218 de 31 de mayo de 1995, núm. 218, cuyo art. 12 dispone genéricamente que el procedimiento civil aplicado en Italia está gobernado por el Derecho italiano.

114 Mayer, P. y Heuze, V., Droit international privé, París, Montchrestien, 2007, p. 492.

115 Baratta, R., «Processo Civile (Legge Regolatrice)», en Baratta, R. (ed.), Dizionari del Diritto Privato, Diritto Internazionale Privato, Milán, Giuffrè Editore, 2010, p. 289.

116 Ibid., p. 290.
} 
no tengan ningún punto de conexión o una estrecha conexión con el Estado en cuestión. En segundo lugar, no precisa los elementos que forman parte de las normas procesales, lo que ha planteado numerosas cuestiones teóricas y prácticas de interpretación (¿cuáles son los elementos que pertenecen exclusivamente al ámbito de la forma? o ¿se debe descartar siempre la aplicación de elementos formales de la ley aplicable extranjera?) ${ }^{117}$. Todas estas cuestiones han tenido que ser resueltas casuísticamente por la jurisprudencia con más o menos acierto ${ }^{118}$, debido también a la ausencia de codificaciones internacionales satisfactorias ${ }^{119}$. En tercer lugar, el principio de soberanía territorial no tiene en cuenta las cada vez más numerosas situaciones donde los actos procesales tienen aspectos extraterritoriales tales como la notificación de la demanda, la prestación de testimonio, la toma en consideración de las normas de competencia extranjeras a efectos de la suspensión de un procedimiento con arreglo a la lex fori o el examen de las normas extranjeras, relativas al reconocimiento y ejecución de sentencias extranjeras, a efectos de la certificación de una demanda colectiva (class action) interpuesta por demandantes que residen fuera del foro ${ }^{120}$.

27. El common law es singular porque integró mucho más tardíamente en su seno el principio de la lex fori regit processum por tres razones: primera, porque, en principio, los tribunales ingleses no tenían competencia ratione personae para decidir sobre casos en los que el demandado residía fuera de la jurisdicción (en un Estado extranjero); segunda, porque había dudas sobre la competencia judicial de los tribunales del common law sobre ciertas cuestiones cuyo planteamiento tenía lugar fuera del territorio inglés; $y$, tercera, porque los tribunales ingleses no reconocían los derechos que habían sido adquiridos con arreglo al Derecho extranjero.

Por tanto, el Derecho del foro (lex fori) se aplicaba tanto a la sustancia como al procedimiento en todos los $\operatorname{casos}^{121}$. Incluso cuando a partir del siglo XVIII Jeremy Bentham estableció la distinción entre "substantive law and adjective law» y se empezó a desarrollar un sistema conflictual de normas que permitiera la admisión y la recepción del Derecho extranjero, los tribunales ingleses interpretaron de forma singular el principio lex fori regit processum. $\mathrm{Al}$ procedimiento, a la forma, se le da preeminencia sobre la sustancia porque aquel se identifica con la evolución histórica del common law, que nació primordialmente como Derecho procesal por medio del sistema de la acción (los

117 CARLIER, P., L'utilisation de la lex fori dans la résolution des conflits de lois, tesis doctoral leída en la universidad de Lille, 2008, párr. 43.

118 GonZÁlez CAMPos, J., "Les liens entre la competénce judiciaire et la competénce législative en droit international privé», RCADI, vol. 156, 1977, pp. 227-376.

119 Por ejemplo, el art. 314 del Código de Bustamante se limita a establecer de forma no exhaustiva que «la ley de cada Estado contratante determina la competencia de los tribunales, así como su organización, las formas de enjuiciamiento y de ejecución de las sentencias y los recursos contra sus decisiones».

120 GARnetT, R., Substance and Procedure in Private International Law, Oxford, Oxford University Press, 2012, p. 14.

121 AILES, E., op. cit., nota 110, p. 400. 
writs y otras clases de forms of action) y de la alegación basada en una sola cuestión (single-issue pleading). Históricamente, el common law no reconoció el Derecho material o sustantivo como existente en abstracto. Ello pertenecía más bien al ámbito de la equity cuyos tribunales resolvían asuntos sin condicionantes formales, pues solo tenían competencia para resolver cuestiones de sustancia o fondo ${ }^{122}$. En cambio, los tribunales del common law únicamente podían resolver cuestiones sustanciales en el contexto de su ejecución procesal, resolvían los asuntos si había un recurso disponible para hacer valer un derecho o para reparar el daño causado (there is no right without a remedy y remedies preceed rights).

Por esta serie de razones, fondo y forma aparecen en el common law entrelazados y superpuestos, de tal modo que el fondo «permaneció oculto entre los intersticios del procedimiento» ${ }^{123}$. Al otorgar ese alcance tan amplio al procedimiento, los tribunales del common law aumentaron consecuentemente el ámbito de aplicación de la lex fori y la cuestión de sustancia/fondo se limitó exclusivamente a la determinación de la existencia o la supresión de un derecho (a right). Solamente ese aspecto podía potencialmente estar gobernado por el Derecho extranjero. En cambio, la forma, el procedimiento, a través del recurso y la reparación, garantizaba al mismo tiempo la solución en cuanto al fondo: si el demandante tenía un derecho debía necesariamente tener a su disposición los medios para hacerlo valer y mantener ese derecho y, además, un recurso para resarcirse del daño que se le hubiera ocasionado en el ejercicio o disfrute de ese derecho ${ }^{124}$.

Además de estas razones históricas, la tradicional aplicación de la regla lex fori regit processum ha recibido en el common law varias justificaciones (algunas coincidentes con los sistemas del Derecho civil): por ser una manifestación de la soberanía territorial ${ }^{125}$, por tener las normas procesales del foro una naturaleza marcadamente imperativa ${ }^{126}$, por ser garantes de la im-

122 MaIn, Th., «Traditional Equity and Contemporary Procedure», Wash. L. Rev., vol. 78, 2003, p. 429; ReQuejo IsIDro, M., Proceso en el extranjero y medidas antiproceso (Antisuit Injunctions), Universidad de Santiago de Compostela, 2000, pp. 27-39.

123 De ahí que John Austin rechazara la distinción entre fondo y forma (Austin, J., Lectures on Jurisprudence, 4. ${ }^{\mathrm{a}}$ ed., Londres, John Murray, 1873: "It cannot be made the basis of a just division"); que John Salmond estimara que muchas normas procesales son «wholly or substantially equivalent to rules of substantive law» (SALMOND, J., Jurisprudence, 9. a ed., Londres, Sweet and Maxwell, 1937, párr. 172); que Walter Cook considerara que casi todas las cuestiones se insertan en una «twilight zone» (CooK, W., «Substance and Procedure in the Conflict of Laws», Yale Law Journal, vol. 42, 1933, p. 333); que Charles Chamberlayne afirmara que «no existe una distinción entre fondo y forma» y que se trata de una distinción «artificial» e «ilusoria» (Chamberlayne, Ch., Modern Law of Evidence, Londres, Sweet and Maxwell, 1911, párr. 171); que Albert Kocourek indicara que la distinción entre sustancia y procedimiento solo tiene sentido en el ámbito limitado de la determinación de los derechos de las partes en un litigio (KocoureK, A., "Substance and Procedure», Fordham Law Rev., vol. 10, 1941, p. 185) y que Thomas Main concluyera que «el procedimiento es inherentemente sustancial y la sustancia es necesariamente formal» (MAIN, Th., "The procedural foundation of substantive law», Wash. L. Rev., vol. 87, 2010, p. 807).

${ }^{124}$ Ashby v. White (1703) 2 LD RAM 938, p. 953.

125 Harding v. Wealands (2007) 2 AC 1, párrs. 73-75 (Lord Rodger).

126 GARNETT, R., op. cit., nota 119, p. 15. 
parcialidad de los tribunales y de la igualdad de trato entre las partes como postulados de la «justicia natural» (natural justice) ${ }^{127}$ o por la simple conveniencia y eficacia del tribunal en cuestión ${ }^{128}$. El gran inconveniente del sistema tradicional del common law es que irremisiblemente ha comprometido la uniformidad del resultado y ha conducido al forum shopping.

Los inconvenientes intrínsecos de la lex fori regit processum, su carácter absoluto, su formulación y aplicación rígida genérica, exclusiva y unilateral, la desigualdad de las ventajas procesales que se generan para las partes en el litigio a costa de la justicia material y las necesidades del dinámico tráfico externo contemporáneo explican la crisis que la lex fori regit processum experimenta en la actualidad. Ha surgido así la idea de que la resolución de las abundantes y complejas cuestiones del tráfico externo requiere el sometimiento de las normas procesales a la flexible y fluida norma de conflicto bilateral. Se trata de una cuestión fundamental que merece ser tratada nivel a nivel doctrinal y aplicada a nivel jurisdiccional ${ }^{129}$.

\subsection{Fondo y forma en la calificación}

28. El carácter absoluto de la regla lex fori regit processum se cuestiona en el contexto de la calificación, cuestión que en estas páginas es abordada aplicando un método comparado que integra en particular la práctica anglosajona. Ello exige al lector que considere no solo la calificación de la lex fori o de la lex causae de los conceptos jurídicos de las reglas de conflicto ${ }^{130}$, sino también desde la perspectiva de reglas calificadas de procesales y reglas calificadas de sustantivas.

29. En los sistemas de Derecho civil, el conflicto fondo/forma en la calificación no se resuelve de manera uniforme. Los tribunales franceses, en general, retienen la calificación con arreglo a la lex fori ${ }^{131}$ desde la famosa decisión de la Cour de Cassation en el asunto Caraslanis c. Caraslanis, donde el alto tribunal francés declaró que la cuestión de si un elemento de la cere-

127 Este justificación no tiene en cuenta que las causas con elementos extranjeros son, por naturaleza, distintas de las causas nacionales. Véase SzÁszY, I., «The Basic Connecting Factor in International Cases in the Domain of Civil Procedure», ICLQ, vol. 15, 1966, núm. 2, pp. 436-456, esp. pp. 446-447.

128 La idea subyacente es que los tribunales nacionales han establecido, de conformidad con la tradición y la costumbre locales, un gran número de prácticas y fórmulas procesales, incluidas la lengua y el ceremonial, que no pueden ser necesariamente comprendidas y, por tanto, aplicadas por los jueces extranjeros: véase Collins, L. (ed.), Dicey, Morris and Collins on the Conflicts of Laws, Londres, Sweet and Maxwell, 2017, apdo. 7004, donde se comentan varias sentencias, incluida la sentencia Shaik Shaied v. Sockalingam Chettiar (1933) AC 342, 346.

129 Graveson, R., «Book Review: International Civil Procedure: A Comparative Study», ICLQ, vol. 17, 1968, núm. 2, pp. 534-535.

${ }_{130}$ Cuando las legislaciones de los Estados no contienen idéntica calificación de las categorías jurídicas, situación bastante frecuente en el caso de la definición de fondo y de forma, se plantea la cuestión del conflicto de calificación, que ha sido descrito como el «drama del Derecho internacional privado»: véase IgLEsias BuHigues, J. L., op. cit., nota 103, p. 874.

131 Esta teoría fue propuesta inicialmente por BARTIN, E., «De l'impossibilité d'arriver à la suppression définitive des conflits de lois», Clunet, vol. 24, 1897, pp. 255-268, 466-495 y 720-760. 
monia matrimonial (la celebración religiosa del matrimonio prevista en la ley griega) era una categoría formal o sustancial debía resolverse con arreglo a los conceptos jurídicos franceses que establecían que la cuestión de la naturaleza civil o religiosa de la ceremonia religiosa era una cuestión de forma ${ }^{132}$.

El ordenamiento jurídico español recoge la orientación jurisprudencial de proceder a la subsunción de los hechos del supuesto litigioso en una categoría jurídica o norma de conflicto, por lo que tradicionalmente «la calificación para determinar la norma de conflicto aplicable se hará siempre con arreglo a la ley española», conforme a lo indicado en el art.12.1 del Código Civil (CC). No obstante, considera la doctrina española que cabe una interpretación flexible que permita tomar en consideración, cuando sea necesario, la ley extranjera (la lex causae) o recurrir a la llamada "calificación autónoma» de los conceptos del Derecho interno o al «reconocimiento en España de las medidas de protección acordadas por otros Estados» (art. 9.6 CC) ${ }^{133}$.

Los tribunales alemanes son los que más interés han demostrado por la calificación de la lex causae ${ }^{134}$ y en la utilización de un método comparativo que implica una doble calificación. En la primera fase, la lex fori alemana determina la norma de conflicto aplicable y, si hay remisión a una institución de la ley extranjera (lex causae) desconocida por la ley alemana, el significado (Sinn) y la importancia de la institución extranjera desconocida (Bedeutung) deben ser valorados/calificados de conformidad con la finalidad perseguida y la función que le atribuye la ley extranjera (lex causae) a esa institución. Y, en la segunda fase, se integra la institución extranjera en las categorías jurídicas alemanas ${ }^{135}$.

30. En los sistemas del common law tampoco existe una solución coherente. En la muy criticada decisión sobre el caso Ogden v. Ogden, la Court of Appeals inglesa caracterizó como cuestión de forma y, por tanto, no aplicable al caso, el requisito del Derecho francés del consentimiento parental previo a la celebración del matrimonio de un menor francés que había contraído válidamente matrimonio con arreglo a la lex loci celebrationis inglesa ${ }^{136}$. Sin

132 Sentencia de 12 de junio de 1955, RCDIP, 1955, p. 723.

133 Ello ha permitido a la Dirección General de Registros y del Notariado (DGRN) incluir en el supuesto de hecho de la norma de conflicto española instituciones desconocidas en el ordenamiento jurídico español como la Kafala marroquí (véase la Resolución de la DGRN de 14 de mayo de 1992, que la asimila al acogimiento en España), y al Tribunal Supremo optar por asimilar el trust del common law a la sucesión mortis causa, aplicándole la regla del art. 9.8 del CC mediante la STS (Sala de lo Civil, Sección $\left.1 .^{\mathrm{a}}\right)$, de 30 de abril de 2008.

134 Inicialmente sugerida en Francia por Despagnet, F., «Des conflits de lois relatifs à la qualification des rapports juridiques», Clunet, vol. 25, 1898, p 253. En Italia la propuso Pacchioni, G., Elementi di Diritto Internationale Privato, Padua, 1930. Y en Alemania la defendió WolfF, M., Private International Law, 2. ${ }^{\text {a }}$ ed., Oxford, Clarendon Press, 1950, pp. 146-147.

135 «Unter Wurdigung ihres Zwecks und ihrer Wirkung vom Standpunkte des auslandishen Rechts aus». Véase la Sentencia del Reichsgericht del 11 de abril de 1940 (RGZ, 1940, 163, p. 367), donde el tribunal alemán aplicó esta forma de proceder en el supuesto de la prohibición de la celebración de contratos entre esposos prevista en la ley extranjera belga aplicable (art. 1595 del Código Civil belga), categoría jurídica desconocida por la lex fori alemana, que prohíbe la celebración de contratos entre esposos: véase ANCEL, B., "L'objet de la qualification», Clunet, 1980, pp. 227 y ss.

136 1904-7, All E. R. 86. 
embargo, debido a la consideración por parte de los tribunales ingleses de la aplicación del Derecho extranjero como una cuestión de hecho a ser alegada por las partes en el citado caso, no se excluyó la posibilidad de que los tribunales ingleses fueran más flexibles en otros supuestos.

Así ocurrió en el caso In Re Cohn, donde se tuvo que decidir si se calificaba como cuestión de fondo o de forma la supervivencia de la madre o de la hija, dos residentes en Inglaterra que estaban domiciliadas en Alemania y que murieron como consecuencia de un ataque aéreo en circunstancias donde era imposible determinar cuál de las dos había muerto antes. Con arreglo a la ley inglesa (Sección 184 de la Law of Property Act de 1925) se presumía que la persona mayor había muerto antes. En cambio, el art. 20 del CC alemán presumía que las muertes eran simultáneas. El foro inglés aplicó las normas de conflicto inglesas que establecían que la sucesión de los bienes muebles se regía por la ley del domicilio (en la causa, la ley alemana) y decidió que la presunción inglesa era una cuestión de fondo/sustancia y no de procedimiento y, por tanto, la lex fori no era aplicable al caso; también calificó la presunción alemana como cuestión de fondo y aplicó la ley extranjera alemana al caso ${ }^{137}$. Por una parte, si la presunción inglesa hubiera sido calificada como cuestión de fondo y la presunción alemana como cuestión de procedimiento, el tribunal no habría aplicado ninguna presunción y los sucesores de la hija no habrían podido reclamar sus derechos a la sucesión de la madre porque no hubieran podido probar que la madre había muerto antes. Y, por otra parte, si la presunción inglesa hubiera sido calificada como cuestión de procedimiento y la presunción alemana como cuestión de fondo, el tribunal inglés habría tenido que resolver el conflicto entre dos presunciones y elegir.

En los Estados Unidos de América prevalece la influencia del common law tradicional y la calificación del fondo y de la forma con arreglo a la lex fori ${ }^{138}$. En el asunto Grant v. Mcauliffe, el Tribunal Supremo de California decidió que, en el ámbito del DI privado, la supervivencia de la causa de una demanda era una cuestión de procedimiento que tenía que ser resuelta con arreglo a la lex fori. Según el tribunal, la supervivencia (cuestión de fondo) no era en sí una parte esencial de la causa de la demanda, sino que estaba relacionada con las normas procesales locales relativas a las condiciones del ejercicio de la acción de responsabilidad por daños y perjuicios que resultaban de la administración de los bienes, derechos y obligaciones de la herencia del causante. Por esa razón, el tribunal californiano descartó la calificación de la cuestión como obligación sustancial extracontractual (tort) gobernada por la norma de conflicto lex loci delicti commissi ${ }^{139}$.

31. La distinción entre fondo y forma tiene consecuencias prácticas en el ámbito del Derecho comparado tanto en la calificación de una norma ju-

137 1944, Ch. 5.

138 Permanece con toda vigencia la exposición de LoREnZEN, E., «The Theory of Qualifications and the Conflict of Laws», Colum. L. Rev., vol. 20, 1920, p. 246.

13941 Cal. 2d 859, 264 P.2d 944 (1953). 
rídica como en la calificación de una cuestión controvertida. La calificación de la norma jurídica puede llevar a situaciones que conduzcan a una laguna jurídica cuando la ley extranjera aplicable sea de naturaleza procesal y la ley del foro sea de naturaleza material; o a una acumulación de la aplicabilidad de las dos leyes (extranjera y del foro) si la lex fori es calificada de naturaleza procesal y la ley extranjera aplicable es calificada de naturaleza material. Aunque los tribunales intentan evitar resultados tan absurdos, los riesgos existen (como lo demuestra el caso In Re Cohn). Precisamente In Re Cohn corrobora que la flexibilidad de la calificación aplicada en el caso no es posible cuando un tribunal califica una ley extranjera con arreglo a sus propios conceptos o cuando el mismo tribunal aplica una calificación extranjera sin poner en tela de juicio las consideraciones de fondo que informan la norma de conflicto del foro ${ }^{140}$.

32. Los analistas anglosajones alegan que los riesgos precitados se eliminan con el método de la calificación limitada a la cuestión controvertida, puesto que el foro solo tiene que identificar esa cuestión e inmediatamente aplicarle un único Derecho ${ }^{141}$. Otra alternativa es la elaboración de leyes que contengan disposiciones "autocalificadoras», como el art. 7.1 de la Personal Injuries Proceedings Act del Estado de Queensland en Australia, que establece que las disposiciones sobre la cuantificación de los daños y perjuicios son cuestiones de fondo y no de procedimiento ${ }^{142}$. En el supuesto de la distinción entre fondo y forma del acto jurídico, el art. 5 del Convenio de La Haya sobre conflictos de leyes en materia de forma de las disposiciones testamentarias, dispone que «a los efectos del presente Convenio, las prescripciones que limiten las formas admitidas de disposiciones testamentarias y que se refieren a la edad, la nacionalidad u otras circunstancias personales del testador, se considerarán como cuestiones de forma. Tendrán la misma consideración las circunstancias que deban poseer los testigos requeridos para la validez de la disposición testamentaria».

También existe la posibilidad de evitar la cuestión de la calificación estableciendo normas de conflicto que determinen la ley aplicable tanto a las cuestiones de fondo como de forma. Los arts. 12.1 y 15 del Reglamento (CE) núm. 593/2008, del Parlamento Europeo y del Consejo, de 17 de junio, sobre ley aplicable a las obligaciones contractuales ${ }^{143}$ (Reglamento Roma I) y del Reglamento (CE) núm. 864/2007, del Parlamento Europeo y del Consejo, de 11 de julio, sobre ley aplicable a las obligaciones extracontractuales ${ }^{144}$ (Reglamento Roma II) incluyen en el ámbito de la norma de conflicto que determina la ley aplicable tanto las cuestiones de fondo (la interpretación, el cumplimiento y extinción de las obligaciones y la reparación/indemnización),

140 Collins, L. (ed.), op. cit., nota 127, apdos. 32-33.

141 Véase Panagopoulos, G, «Substance and Procedure in Private International Law», JPIL, vol. 1, 2005, pp. 74-75.

142 GaRnETT, R., op. cit., nota 119, apdo. 3.07.

143 DO núm. L 177, de 4 de julio de 2008.

144 DO núm. L 199, de 31 de julio de 2007. 
como algunas cuestiones de procedimiento (las medidas procesales que puede adoptar un tribunal para garantizar la prevención, el cese o la reparación de un daño o las normas sobre los plazos de prescripción y caducidad). Sin embargo, ninguno de los dos Reglamentos logra eliminar completamente la cuestión de la calificación: continúa siendo pertinente en los supuestos de la «prueba»y del «proceso» (art. 1.3), cuyo significado no precisan los Reglamentos. La calificación también continúa siendo relevante en las cuestiones relativas a las presunciones legales y a la carga de la prueba en los términos previstos en el art. 18.1 del Reglamento Roma I y el art. 22.1 del Reglamento Roma II.

Finalmente, otra alternativa es recurrir a la elaboración de conceptos generales, autónomos e independientes producto del estudio del Derecho comparado o que respondan a criterios de uniformidad en un marco de integración regional (teoría de la autonomía) ${ }^{145}$ y, en particular, de la $\mathrm{UE}^{146}$.

\subsection{Fondo y forma en la aplicación de la ley extranjera}

33. La aplicación de la ley extranjera puede verse afectada/limitada cuando se la condiciona a ciertos requisitos formales del foro. Así ocurre cuando se atribuye a las partes el deber de probar el contenido y vigencia del Derecho extranjero (art. 281 de la LEC), cuando se establecen las condiciones a las que el juez debe atenerse en cuanto al conocimiento del Derecho extranjero (el alcance del principio iura novit curia) o el acceso a la información del contenido del Derecho extranjero (la solicitud de información por parte de los órganos judiciales, notarios y registradores previstas en los arts. 34-35 de la Ley española de Cooperación Jurídica Internacional en Material Civil).

34. En el ámbito procesal, es fundamental la distinción entre las cuestiones de hecho y las cuestiones de Derecho, porque dependen de esa calificación: la determinación de quién está obligado a introducir ciertas cuestiones en el procedimiento (las partes si se trata de una cuestión de hecho o el órgano judicial si se trata de una cuestión de Derecho); la exigencia o no de prueba (las cuestiones de hecho deben ser probadas por las partes y las cuestiones de Derecho se rigen por el principio jura novit curia); o el alcance de la competencia de los tribunales de apelación (posibilidad de resolución de las alegaciones de Derecho material e imposibilidad de resolución de las alegacio-

145 Inicialmente propuesta en Alemania (RABEL, E., "Das Problem des Qualifikation», Rabels Z., 1931, p. 241) y en Inglaterra (BECKETT, W.-E., "The Question of Classification in Private International Law», BYbIL, vol. 15, 1934, pp. 46-81, esp. pp. 58-60).

146 Asuntos C-154/15, C-307/15 y C-308/15, ECLI:EU:C:2016:980. En esta sentencia el TJUE señala que «es preciso distinguir la aplicación de una regla procesal — como es un plazo razonable de prescripción- de la limitación en el tiempo de los efectos de la interpretación de una norma del Derecho de la Unión» y "habida cuenta de la exigencia fundamental de una aplicación uniforme y general del Derecho de la Unión, el Tribunal de Justicia es el único que puede decidir acerca de las limitaciones en el tiempo que hayan de aplicarse a la interpretación que él mismo haya hecho de una norma del Derecho de la Unión». 
nes fácticas). El examen comparado de los distintos ordenamientos jurídicos demuestra cómo nos encontramos lejos de alcanzar una solución uniforme.

Existe una división entre los ordenamientos jurídicos que consideran el Derecho extranjero como Derecho y los que lo consideran como hecho. El Derecho procesal alemán considera al Derecho foráneo como una cuestión de Derecho, aunque precisa que si el juez desconoce el contenido de una ley extranjera esta debe ser probada (art. 293 de la Zivilprozessordung) ${ }^{147}$. Por su parte, el Derecho inglés se basa en el principio de que el Derecho extranjero debe ser tratado como una cuestión de hecho, ficción histórica originada por la ausencia de competencia de los tribunales del common law para resolver litigios con elementos extranjeros, lo que acarrea dos consecuencias: primera, la integración en la prueba de la acreditación del conocimiento y contenido del Derecho extranjero ( $"$ The way of knowing foreign laws is by admitting them to be proved as facts» $)^{148} \mathrm{y}$, segunda, la posibilidad de ejercitar recursos de apelación contra las sentencias que no hayan aplicado correctamente el Derecho extranjero. A mi juicio, esas diferencias entre los ordenamientos jurídicos tienen una importancia relativa: en la práctica todos atribuyen a la cuestión un carácter mixto, a la vez sustancial y procesal, ya sea mediante la aplicación del Derecho extranjero como un Derecho especial distinto de la ley del foro o como un hecho de naturaleza especial.

35. En cambio, sí que tiene efectos prácticos diferenciados la cuestión de la decisión de cómo el juez procede a la introducción del Derecho extranjero en el proceso. Muchos ordenamientos jurídicos consideran procesales las cuestiones relativas a la invocabilidad del Derecho extranjero.

El Derecho alemán se atiene a la exigencia de que el juez proceda a la aplicación de oficio del Derecho extranjero convocado por la norma de conflicto ${ }^{149}$, aunque también admite la autonomía de la voluntad de las partes para alegar ante el juez, en el marco de sus pretensiones sobre los hechos y las pruebas. Si las partes no alegan en sus pretensiones el Derecho extranjero aplicable al caso, un tribunal alemán no lo hará motu propio, lo que significa que la ley procesal del foro permite a las partes elegir la lex fori más allá de los límites fijados por la autonomía de las partes en el DI privado (Verhandlungsgrundsatz). Este no es el caso de los asuntos sometidos al proceso inquisitivo (Untersuchungsgrunsatz), pues este se mantiene exclusivamente en las manos del juez que actúa de oficio ${ }^{150}$.

La posición del Derecho francés es más complicada y puede resumirse en tres principios: los tribunales franceses aplican el Derecho extranjero alegado y probado por las partes; si las partes no lo invocan, los tribunales lo

\footnotetext{
147 KROPholler, J., Internationales Privatrecht, Tubinga, Mohr Siebeck, 2007, sec. 31.I.

148 Mostyn v. Fabrigas (1774), 1 Cowper's King's Bench Reports 161, p. 174 (Lord Mansfield).

149 Sentencia del Reichsgericht de 28 de mayo de 1936, JW (1936), p. 2059. Véase Kropholler, J., op. cit., nota 146, sec. 7.II.2.

${ }^{150}$ Hausmann, R., "Pleading and Proof of Foreign Law-A Comparative Analysis», The European Legal Forum, vol. 1, 2008, pp. 3-4.
} 
aplican de oficio en los supuestos en los que las partes no tienen la facultad de disponer libremente de sus derechos (droits indisponibles) (art. 12.1 del Code de procédure civile); en cambio, cuando el asunto concierna supuestos gobernados por el ius dispositivum los tribunales franceses no tienen la obligación de aplicar de oficio el Derecho extranjero ${ }^{151}$, a no ser que el Derecho convencional o europeo dispongan lo contrario y no exista un pacto procesal expreso entre las partes para aplicar la ley del foro francés ${ }^{152}$. En España, a pesar de lo dispuesto en el art. 12.6 del CC, el legislador asume la atribución a las partes del deber de probar al juez el contenido y la vigencia del Derecho extranjero (art. 281.2 LEC) ${ }^{153}$.

En Inglaterra, los tribunales no tienen competencia ni obligación para aplicar el Derecho extranjero ex officio ${ }^{154}$ y este solo se aplica como parte de cualquier otro hecho cuando las partes lo invocan voluntariamente ante el juez en virtud de la llamada default rule o norma no imperativa cuyo contenido puede prescindirse en virtud del ejercicio de la autonomía de la voluntad. Si no hay tal invocación, el juez se atiene a la aplicación de la ley inglesa del foro incluso cuando la norma de conflicto remita a la aplicación del Derecho extranjero $^{155}$. Ello es así por dos razones: por un lado, el common law se rige por un sistema acusatorio (adversarial principle) que impone a los jueces el deber de ceñirse exclusivamente a la información y las pruebas que presenten las partes y, por otro lado, los contendientes a menudo se abstienen de invocar una ley extranjera que les es desfavorable o debido a la complejidad de las normas de conflicto inglesas y la incertidumbre de su resultado.

Por lo que respecta el Derecho de la UE, existe controversia sobre la cuestión de si el Reglamento Roma I (vigente en todos los Estados miembros de la UE salvo Dinamarca, que se rige por el Convenio Roma I de paralelo contenido), afecta al Derecho de los Estados sobre la invocabilidad del Derecho extranjero, teniendo en cuenta que el Reglamento «se aplicará a las obligaciones contractuales en materia civil y mercantil en las situaciones que impliquen un conflicto de leyes» (art. 1.1) y que "el contrato se regirá por la ley eligida por las partes» (art. 3.1). La solución parece dada por el propio Reglamento Roma I en su art. 1.3, que excluye su aplicación a la «prueba» y al «proceso», lo que implica la exclusión de las cuestiones de invocabilidad de la aplicación de la ley extranjera puesto que, como hemos señalado, muchos ordenamientos jurídicos las tratan como cuestiones procesales ${ }^{156}$.

151 Sentencia de la Cour de Cassation de 4 de diciembre de 1990, Clunet, 1991, p. 371.

152 Sentencia de la Cour de Cassation de 6 de mayo de 1997, Rev. Criti., 1997, p. 514.

153 Esplugues Mota, C., Iglesias Buigues, J. L. y Palao Moreno, G., Derecho internacional privado, Valencia, Tirant, 2017, pp. 249 y ss.

154 Fremoult v. Dedire (1718) 1 P. Wms., p. 429.

155 Aluminium Industrie Vaasen B. V. v. Romalpa Aluminium Ltd. (1976) 1 WLR 676, CA.

156 Esplugues Mota, C., Iglesias Buigues, J. L. y Palao Moreno, G., Application of Foreign Law, Múnich, Sellier Europea Law Publishers, 2011. El libro contiene un estudio detallado de la cuestión en todos los Estados miembros de la UE, así como un informe general sobre la aplicación del Derecho extranjero (pp. 3-94); y HARTLEY, T. C., «Pleading and Proof of Foreign Law: the Major Legal Systems Compared», ICLQ, vol. 45, 1996, núm. 2, pp. 271-292, esp. p. 288. 
36. También es procesal la cuestión de la llamada prueba del Derecho extranjero, es decir, la acreditación del contenido y vigencia del Derecho extranjero en el marco del proceso civil. La solución depende de la naturaleza que el Derecho procesal del foro le otorgue a la ley foránea; como un hecho, un derecho o una naturaleza «híbrida» (caso español). En los ordenamientos jurídicos donde la ley extranjera es aplicada como derecho, el juez la debe aplicar de oficio y esa obligación conlleva la prueba, es decir, la acreditación y vigencia de su contenido. En los ordenamientos jurídicos donde el Derecho extranjero se considera como una cuestión de hecho y solo se aplica si es invocado por las partes, la carga de la prueba incumbe a la parte que la invoca; en ausencia o defecto en la acreditación del Derecho extranjero, el tribunal aplica la lex for ${ }^{157}$.

\subsection{La conflictualización de la lex fori regit processum}

37. Muchos escritores, tribunales y legisladores han asumido que las cuestiones procesales no pueden ser resueltas por el método conflictual, por una norma de conflicto de carácter bilateral. Se piensa que, puesto que el procedimiento y el Derecho del foro forman una ecuación, las reglas procesales extranjeras nunca pueden ser admitidas en el foro y, por tanto, nunca pueden entrar en conflicto con las reglas procesales del foro.

Esta corriente de pensamiento es defectuosa, tanto desde el punto de vista práctico como de los principios. En primer lugar, hay cada vez más casos donde, en el contexto de la aplicación del Derecho procesal del foro, las normas procesales extranjeras son aplicadas o, por lo menos, reconocidas por los tribunales del foro. Por ejemplo, cuando se practica la prueba testimonial de extranjeros en el supuesto en el que la información sobre la prueba documental extranjera no se pueda obtener en el foro o cuando el foro determina su competencia internacional basándose en las reglas procesales donde un tribunal extranjero ejercería su competencia. En segundo lugar, hay circunstancias en las que el alcance de las normas procesales del foro está limitado por la remisión a la ley extranjera. Por ejemplo, en el supuesto en el que el tribunal del foro rechaza la notificación de una citación judicial a una persona que se encuentra en el extranjero, cuando la comunicación de dicha citación violaría la ley extranjera del Estado en donde se encuentra. También en el supuesto en el que el tribunal del foro reconoce determinados actos procesales dictados por tribunales extranjeros cuando, de no hacerlo, los derechos y obligaciones de las partes se verían afectados por las reglas procesales sobre la notificación y citación judicial de dichos actos en vigor en esos Estados.

38. Algunos observadores estudiosos del common law han admitido que se produce una conflictualización incluso en los casos en los que el Derecho procesal del foro no es reemplazado por el extranjero, sino que es simplemente modificado para tomar en consideración ese Derecho extranjero.

157 Hausmann R., op. cit., nota 149, pp. 7-13. 
Se trata de la doctrina de la "lex fori ilustrada» (enlightened lex fori), que expuso Otto Kahn-Freund, en los supuestos en los que el tribunal del foro abandona la aplicación de algunos requisitos procesales técnicos previstos en la lex fori para tomar en consideración conceptos generales de la ley extranjera $^{158}$. También es pertinente la doctrina del «datum» propuesta por Herma Kay (reminiscente de la teoría del datum de Anton Erenzweig) ${ }^{159}$, que permite al foro tomar conocimiento del Derecho extranjero en el contexto de la aplicación del Derecho del foro ${ }^{160}$. Estas corrientes han sido consideradas artificiales por quienes estiman que toda norma jurídica contiene a la vez hechos y derechos ${ }^{161}$. En particular, en los Estados Unidos de América, la distinción entre sustancia y procedimiento ha demostrado ser inadecuada e insuficiente para resolver las cuestiones relativas a la capacidad procesal y la capacidad para ser parte, la validez formal de documentos y negocios jurídicos, los llamados privilegios procesales (privilege rights) y el establecimiento cuantificable de los daños. Por esa razón, la distinción ha sido abandonada gradualmente, diluida en el proceso de la aplicación de normas de conflicto bilaterales que contienen puntos de conexión flexibles (less hard and fast rules), que remiten a la ley que tiene una relación más significativa con el caso (the most significant relationship or closest connection principle).

39. Muy especialmente merece ser destacado el esfuerzo de la UE ${ }^{162}$. El Reglamento (UE) núm. 1215/2012, del Parlamento Europeo y del Consejo, de 12 de diciembre, relativo a la competencia judicial, el reconocimiento y la ejecución de resoluciones judiciales en material civil y mercantil (Reglamento núm. 1215/2012), que se aplica en todos sus Estados miembros (salvo Dinamarca) ${ }^{163}$, ha facilitado el acceso a la justicia mediante la unificación de las normas sobre conflictos de jurisdicción en materia civil y mercantil (unificación que ha tenido efectos beneficiosos en el Derecho inglés), mediante la interpretación autónoma (y extensiva) por el TJUE ${ }^{164}$ de los términos «materia civil y mercantil» y de los demás términos del Reglamento núm. 1215/2012 «refiriéndose, por una parte, a los objetivos y al sistema del propio reglamento y, por otra, a los principios generales que se deducen de todos los sistemas jurídicos nacionales» ${ }^{165}$ y mediante la instauración del reconocimiento y la ejecución rápida y simple de las resoluciones judiciales, sin procedimientos especiales (supresión del exequatur), dictadas en los Estados miembros ${ }^{166}$.

\footnotetext{
158 Kahn-Freud, O., General Problems of Private International Law, Leiden, Sijthoff, 1976, p. 227.

159 Ehrenzweig, A., Private International Law. A Comparative Treatise on American International Conflicts Law, Including the Law of Admiralty, Nueva York, Oceana Publications, 1967, pp. 39-49.

160 KAY, H., "Foreing Law as Datum», California Law Rev., vol. 53, 1965, p. 47.

161 Jansen, N. y Michaels, R., «Die Auslegung und Fortbildung ausländischen Rechts», Zeitschrift für Zivilprozeß, vol. 116, 2003, pp. 8-16.

162 Hess, B., «El efecto de Integración Europea del Derecho Procesal Civil», Revista Europea de Reforma Legal, vol. 4, 2002, núm. 1, pp. 13-14.

${ }^{163}$ DO L núm. 315, de 20 de diciembre de 2012. Sus normas de competencia judicial son aplicables desde el 10 de enero de 2015.

164 Asunto C-292/08, ECLI:EU:C:2009:544.

165 Asunto C-551/15, ECLI:EU:C:2017:193, párr. 33.

166 Requejo Isidro, M., «La ejecución sin exequátur. Reflexiones sobre el Reglamento, Bruselas I bis», Capítulo III, REDI, vol. 67, 2015, núm. 2, pp. 49-82. Confrontar el Auto de la Audiencia
} 
En particular, el art. 7.2 del Reglamento núm. 1215/2012 contiene una regla de conflicto procesal competencial de carácter bilateral al disponer que una persona domiciliada en un Estado miembro podrá ser demandada en otro Estado miembro «en materia delictual o cuasidelictual, ante el órgano jurisdiccional del lugar donde se haya producido o pueda producirse el hecho dañoso». El mismo contenido bilateral imperativo tiene su art. 4, al disponer que la competencia de los tribunales está determinada por la del domicilio de las personas en cualquier Estado miembro, sea cual sea su nacionalidad, salvo que el propio reglamento disponga otra cosa ${ }^{167}$. La armonización de los sistemas nacionales introducida por el Reglamento núm. 1215/2012 explica que se descarten, por innecesarias y por atentar contra la seguridad jurídica, excepciones como la doctrina del forum non conveniens de los sistemas del common law, basada en la cortesía recíproca (comity) entre los tribunales. Ello porque, a pesar de que esta excepción funciona como una verdadera arma procesal contra el forum shopping, al permitir a los órganos judiciales de un Estado inhibirse y suspender provisionalmente el proceso en favor de un órgano jurisdiccional situado en otro Estado, deja un amplio margen de apreciación al juez que conoce del asunto para decidir si un foro extranjero es el más adecuado para resolver el fondo del litigio sobre el que también es competente ${ }^{168}$. Según el TJUE, la admisión de este tipo de excepciones, además de conculcar el principio de la seguridad jurídica y de la previsibilidad de las reglas de competencia establecidas en el Reglamento núm. 1215/2012, pondría en peligro la aplicación uniforme de estas últimas, en la medida en que solamente un número limitado de Estados miembros reconoce dicha excepción, siendo así que el objetivo del Reglamento núm. 1215/2012 es precisamente establecer reglas comunes y excluir las reglas nacionales exorbitantes ${ }^{169}$.

Tanto el Reglamento Roma I como el Reglamento Roma II dan amplio margen al sometimiento de ciertas normas procesales al método conflictual de carácter bilateral, en particular a la ley aplicable al fondo. Así, por ejemplo, las consecuencias del incumplimiento total o parcial de las obligaciones, incluida la cuestión de la naturaleza y evaluación del daño, se rigen por la ley contractual elegida por las partes «dentro de los límites de los poderes conferidos al tribunal por su Derecho procesal» (art. 12 del Reglamento Roma I) o por ley aplicable a la obligación extracontractual que regula «la existencia, la naturaleza y la evaluación de los daños o la indemnización solicitada»(art. 15 del Reglamento Roma II). Las mismas normas se aplican a

Provincial de San Sebastián, Sección $2 .^{\text {a }}$, de 8 de marzo de 2018, que estima el recurso de apelación interpuesto contra un auto del Juzgado de Primera Instancia, revocando el mismo y, en su lugar, dicta nueva resolución por la que no se accede a la solicitud de adopción de medidas cautelares. La resolución impugnada había basado las medidas cautelares en la suspensión de un procedimiento iniciado en Francia, en aplicación del art. 35 del Reglamento núm. 1215/2012.

167 Sobre el carácter obligatorio del sistema de competencia establecido por el art. 2 del Convenio de Bruselas, formulado en términos idénticos al art. 2 del Reglamento núm. 1215/2012: véanse los asuntos C-116/02, ECLI:EU:C:2003:657, párr. 72 y el C-159/02, ECLI:EU:C:2004:228, párr. 24.

168 Spiliada Maritime Corporation/Cansulex Ltd. (1987) AC 460, p. 476.

169 Asunto C-281/02, ECLI:EU:C:2005:120, párrs. 37 y ss. 
los diversos modos de extinción de las obligaciones y, en particular, la prescripción y la caducidad basadas en la expiración de un plazo [art. 12.1.d) del Reglamento Roma I y art. 15.h) del Reglamento Roma II]. Finalmente, ambos reglamentos consagran la validez formal del contrato, o del acto jurídico unilateral relativo a la obligación extracontractual, «si reúne los requisitos de forma de la ley que lo rija en cuanto al fondo [...], o de la ley del país donde se haya celebrado (lex loci actus)» (art. 11.1 de Roma I y art. 21 de Roma II). Quedan excluidas de su ámbito de aplicación las cuestiones relativas «a la prueba»o «al proceso» (art. 1.3), por lo que la distinción entre fondo y forma vuelve a ser pertinente en estos supuestos ${ }^{170}$.

En términos generales, la exclusión de la prueba y el procedimiento de su ámbito de aplicación, la ausencia de definición autónoma de esos términos y su limitación ratione materiae a las obligaciones contractuales y extracontractuales, hacen pensar que muchas cuestiones no están resueltas por esos instrumentos y que deberán serlo según la ley nacional ${ }^{171}$. Sin embargo, ya es de por sí significativo que el legislador de la UE no haya establecido que las cuestiones relativas a la prueba y al procedimiento sean resueltas con arreglo a la lex fori. Aunque la aplicación de la lex fori sería el obvio resultado del sistema conflictual inglés, en los otros sistemas jurídicos sería posible que un tribunal nacional pudiera calificar, como fondo o sustancia, con arreglo a la lex causae las cuestiones relativas a la admisibilidad de la prueba. Alternativamente, la obtención de una prueba en un Estado extranjero podría ser calificada como cuestión de forma/procedimiento regida, al menos en parte, por una ley distinta de la lex fori. En cualquier caso, para paliar los posibles efectos negativos, Martin Illmer propone la elaboración de una visión sobre la prueba y el proceso que sea autónoma y que se fundamente en la idea de neutralidad: un tribunal nacional debe aplicar la lex causae para resolver cualquier cuestión que interese o afecte a la decisión sobre el fondo y la lex fori a cualquier cuestión que concierta el modo o a la conducta del proceso ante el tribunal ${ }^{172}$.

Indudablemente la legislación de la UE ha reducido el amplio ámbito que la lex fori regit processum tenía en el sistema conflictual del common law inglés al basarse en la aplicación estricta de la distinción tradicional entre derecho y recurso/acción distinción que todavía predomina en varios países del common law y en algunos Estados de los Estados Unidos de América ${ }^{173}$. Ac-

170 Salvo lo dispuesto en el art. 18.1 del Reglamento Roma I y el art. 22.1 del Reglamento Roma II, que establecen que la ley que rija las correspondientes obligaciones «se aplicará en la medida en que, en materia de obligaciones contractuales/extracontractuales, contenga normas que establezcan presunciones legales o determinen la carga de la prueba» $\mathrm{y}$ «que tal medio de prueba pueda emplearse ante el tribunal que conozca del asunto».

171 ILlmer, M., «Neutrality matters - some thoughts about the Rome regulations and the so-called dichotomy of substance and procedure in European private international law», Civil Justice Quarterly, vol. 28, 2009, pp. 241-243.

172 Ibid., pp. 246-247.

173 Huber v. Steiner (1835) 2 Bing NC 202, p. 210: "So much of the law as affects the rights and the merit [...] all that relates ad litis decisionem is adopted from the foreign country; so much of the law as 
tualmente la doctrina, los legisladores y los tribunales de Inglaterra, Australia, Canadá y algunos Estados de los Estados Unidos de América invocan razones casuísticas, de conveniencia o de eficacia procesal para calificar como sustanciales todas las disposiciones que no estén dirigidas a reglamentar la conducta o modo del proceso ${ }^{174}$. La influencia de los reglamentos de la UE es tal en materia extracontractual, que algunos jueces y tribunales ingleses han establecido que si se acepta la premisa de que la ley aplicable al daño no es la lex fori sino la ley designada por la norma de conflicto (the proper law of the tort), la remisión a la lex fori "debe ser la excepción y su aplicación requiere ser justificada por alguna razón imperativa» ${ }^{175}$.

En contraste con los sistemas del common law, en los sistemas de Derecho civil los efectos de los reglamentos de la UE no han sido tan significativos. Ello se debe a que esos sistemas se han mostrado tradicionalmente más comprensivos sobre la relevancia del Derecho extranjero para resolver cuestiones procesales tales como algunos supuestos de la capacidad procesal, la capacidad para ser parte, la legitimación, la representación procesal y la postulación (arts. 9.1, 9.11 y 11 del CC) y más abiertos a la ratificación de convenios internacionales armonizadores como los que simplifican la notificación judicial de actos procesales (el Convenio de La Haya, sobre procedimiento civil o el Convenio de La Haya, relativo a la notificación o traslado de documentos judiciales y extrajudiciales en materia civil o comercial) o como el Reglamento (CE) núm. 1393/2007, del Parlamento Europeo y del Consejo, de 13 de noviembre, relativo a la notificación y al traslado en los Estados miembros de documentos judiciales y extrajudiciales en materia civil o mercantil en los Estados miembros de la UE ${ }^{176}$.

Además de la labor de la UE, la conflictualización de las normas procesales también se ha visto facilitada por la interpretación armonizadora que realiza el TEDH de las garantías procesales fundamentales y, en particular, del derecho a un proceso equitativo previsto en el art. 6 del CEDH, que incluye el derecho al juicio equitativo o justo ante los tribunales, el derecho a la presunción de inocencia y los derechos del acusado dentro del proceso penal. El TEDH determina las pautas a las que han de atenerse las jurisdicciones locales europeas y, aunque no está destinado a sustituirlas en forma alguna ni a convertirse en una última instancia, la adecuada difusión de sus criterios jurisprudenciales es imprescindible para que los tribunales nacionales puedan aplicarlos directamente, evitando y limando diferencias, como así ha sido en lo que respecta a principios como el acceso a la justicia, la tutela

affects the remedy only, all that relates ad Litis ordinationem, is taken from that country where the action is brought".

${ }^{174}$ Harding v. Wealands (2005) 1 WLR 1539 Revd (2007) 2 AC 1; McKain v. RW Miller Co. (south Australia Pty Ltd 81991) 174 CLR 1, 26-27. También en Pfeiffer Pty Ltd v. Robertson (2000) 203 CLR 503 párr. 97-99. Véase GARNETT, R., op. cit., nota 119, p. 38, apdo. 2.51.

175 Pfeiffer Pty Ltd v. Robertson (2000) 203 CLR 503, párr. 52.

176 DO núm. L 324, de 10 de diciembre de 2007. En España, la LEC (art. 177), la Ley 7/2015 por la que se modifica la Ley Orgánica del Poder Judicial (arts. 267-278) y la Ley 29/2015 de Cooperación Jurídica Internacional en materia civil. 
judicial efectiva, el juicio justo/juicio equitativo, la audiencia (o a ser oído), el proceso debido (due process), el "proceso garantizado por la ley», el derecho de defensa procesal o el plazo razonable entendido como el derecho a un proceso sin dilaciones indebidas ${ }^{177}$.

40. Finalmente, algunas instituciones no gubernamentales como el American Law Institute y el Instituto Internacional para la Unificación del Derecho Privado han propuesto una serie de principios y reglas transnacionales de procedimiento (Principles and Rules of Transnational Civil Procedure) ${ }^{178}$. Estos principios se basan en la iniciativa del denominado Grupo Storme ${ }^{179}$ y se presentan como un conjunto de procedimientos «universales», a medio camino entre los ordenamientos de Derecho civil y los del common law.

Los principios abordan de satisfactoriamente ciertas cuestiones importantes sobre el contenido y forma de la demanda, los procedimientos y medios de prueba y el proceso de decisión. Sin embargo, no suprimen completamente el imperio de la lex regit processum puesto que admiten específicamente que «el Derecho procesal del foro se aplica a los litigios no regulados específicamente por estos Principios» (Principio I) ${ }^{180}$. Tampoco abordan cuestiones procesales importantes como la cuestión de la «especificación suficiente» (notice pleading), es decir, el escrito breve y simple de notificación de la demanda y de la contestación de la demanda previsto en las Federal Rules of Civil Procedure estadounidenses. Finalmente, algunos de los principios amparan normas procesales, como el deber del tribunal de incentivar el acuerdo entre las partes cuando sea "razonablemente posible», que pertenecen a la tradición de algunas jurisdicciones del common law (la Sección 36 de las Civil Procedure Rules inglesas), pero que en cambio se apartan de la tradición de algunos Estados donde las partes no tienen, generalmente, ni la obligación de negociar ni la de considerar propuestas de acuerdo formuladas por la otras partes.

41. En suma, la conflictualización de la lex regit processum a nivel universal obedece a las necesidades del tráfico externo y a una serie de cambios que anuncian la creación de una nueva jerarquía de principios procesales y sustanciales: control judicial reforzado sobre el desarrollo del procedimiento civil, que ha modificado su carácter predominantemente privado en favor de una coloración pública; tendencia hacia la supresión de restricciones arcaicas sobre la introducción y valoración de la prueba y su sustitución por la investigación de los hechos (fact finding); la constitucionalización y la internacionalización de las llamadas «garantías procesales»; una tendencia

177 Díaz Aparicio c. España, núm. 49468/99, TEDH 2001; Becker c. Alemania, núm. 45448/99, TEDH 2002; Wejrup c. Dinamarca (dec.), núm. 49126/99, TEDH 2002; Georgiades c. Chipre (dec.), núm. 62233/00, TEDH 2002; Bendayan Azcantot y Benalal Bendayan c. España, núm. 28142/04, TEDH 2009; y Serrano Contreras c. España, núm. 49183, TEDH 2012.

178 ALI/UNIDROIT, Principles and Rules of Transnational Civil Procedure, Cambridge, Cambridge University Press, 2005.

179 Storme, M. (ed.), Rapprochement du droit judiciaire de l'Union européenne, Leiden, Nijhoff, 1994.

180 GARnETT, R., op. cit., nota 119, párr. 33.1-3. 
universal de transferencia de un número importante de asuntos, que tradicionalmente han sido clasificados como de naturaleza civil y resueltos por tribunales ordinarios, al ámbito de los tribunales y agencias administrativas y de los tribunales arbitrales; y una irrupción del «access to justice movement» apoyado en valores de justicia material y una preocupación por la calidad de la justicia procesal.

\section{CONCLUSIONES}

42. La existencia y permanencia del conflicto entre fondo y forma obedece a siglos de controversias y litigios de carácter político y económico. Desde la perspectiva jurídica, han coexistido tradicionalmente dos modos de tratar la distinción entre fondo y forma: el método formal favorece la utilización de reglas generales claramente definidas y altamente administrables; el método substancial se basa en la aplicación de principios de justicia material en las decisiones individuales a las que se les otorga un escaso valor de precedente. Las concepciones altruistas sobre las cuestiones de fondo recurren a valores morales en la administración de la justicia, mientras que las concepciones individualistas ponen el énfasis en la armonización de normas.

43. El análisis de la práctica que se ha llevado a cabo en las páginas precedentes demuestra cómo la sociedad está experimentando cambios sociales, económicos y jurídicos que contribuyen a la fluidez y permeabilidad entre las fronteras del fondo y de la forma. Por tanto, el conflicto entre fondo y forma en el DI publico y el DI privado no puede basarse en definiciones rígidas y estancas ni reducirse a diferencias sobre cómo aplicar un cálculo neutral que maximice el total de las satisfacciones que se otorguen a las válidas necesidades humanas. Fondo y forma se necesitan mutuamente, pues son interdependientes y ninguno de los dos tiene gran valor autónomamente. El equilibrio en esa interdependencia se ha de determinar casuísticamente, en paralelo a la evolución social, económica y jurídica.

44. La conexión entre forma y sustancia, entre el derecho de procedimiento y el derecho sustantivo es comprensible porque ambos son resultado y reflejo de los objetivos sustanciales de una sociedad. El derecho de procedimiento puede ser adjetivo y, además, el procedimiento puede consistir en una colección de técnicas. Pero no hay ninguna técnica jurídica que constituya una finalidad en sí misma y ninguna técnica jurídica es neutral desde el punto de vista ideológico. El impacto de la ideología sobre el derecho de procedimiento depende del punto de vista ideológico de la relación entre los Estados o entre los individuos y la sociedad internacional.

45. Todo este sustrato explica las contradicciones e inseguridades que se producen en la aplicación y la interpretación de la distinción entre fondo y forma en el DI público y el DI privado, aunque no aminora la necesidad de su gradual e irrenunciable perfeccionamiento. 


\section{RESUMEN}

\section{CONSIDERACIONES EN TORNO A LA DISTINCIÓN ENTRE EL FONDO Y LA FORMA EN EL DERECHO INTERNACIONAL (PÚBLICO Y PRIVADO)}

La distinción entre el fondo y la forma basada en criterios rígidos y estancos ha cobrado renovada actualidad debido a una serie de pronunciamientos jurisprudenciales polémicos que han introducido requisitos formales desproporcionados en el ámbito del DI público, han puesto en tela de juicio su tradicional flexibilidad informal y han desequilibrado la necesaria realización de la justicia como conjunto unitario y ecuánime, a la vez procesal y material, en el Estado de Derecho internacional. Sin embargo, el análisis de la práctica internacional demuestra que la realización de la justicia internacional en la fase actual de cambios que experimenta la comunidad internacional requiere una fluida permeabilidad entre las fronteras del fondo y de la forma que se han convertido en interdependientes, ya que ninguno de las dos tiene gran valor autónomamente. Paralelamente, en el ámbito del DI privado, las necesidades del actual dinamismo del tráfico externo de los particulares y operadores económicos privados han expuesto la incapacidad e insuficiencia de la regla lex fori regit processum, en su tradicional formulación y aplicación exclusiva y unilateral, para evitar el trato desigual de las partes en el litigio y la frustración de la justicia material. Ante la ausencia de principios y reglas transnacionales procesales válidas universalmente, algunos legisladores y tribunales nacionales y, en particular la UE, han iniciado un loable desarrollo de normas de conflicto bilaterales de naturaleza procesal para resolver cuestiones pertinentes, particularmente de calificación y de aplicación de la ley extranjera.

Palabras clave: fuentes del DI, desafío formalista, jurisdicción, competencia y acceso a la justicia internacional, responsabilidad y reparación, jus cogens, agotamiento de los recursos internos, terrorismo internacional, protección del medio ambiente, derechos humanos, lex fori regit processum, calificación, ley extranjera, normas de conflicto bilaterales, principios procesales y materiales.

\section{ABSTRACT \\ CONSIDERATIONS ON THE DISTINCTION BETWEEN FORM AND SUBSTANCE IN INTERNATIONAL LAW (PUBLIC AND PRIVATE)}

The distinction between form and substance based on watertight, rigid criteria has experienced a renewed actuality owing to a series of controversial international judgments that have introduced disproportionate formal requirements in the field of public international Law. These new formal conditions have put into question the traditional informal flexibility of public international law and have impaired the realization of fairness as a unitary and impartial corpus, both procedural and substantive, within the international Rule of Law. Notwithstanding, an analysis of the relevant international practice demonstrates that the quest for international justice at the present stage of change that the international community is experiencing, demands a fluid permeability between the frontiers of form and substance, which have become interdependent and without great value when applied autonomously. Simultaneously, in the field of private International Law, the requirements of the present dynamism of the international relations and transactions between private individuals and economic operators have revealed the failure and inadequacy of the rule lex fori regit processum, as formulated and applied in its traditional, unilateral and exclusive scope, both for the purpose of assuring equal treatment between the parties in a dispute and for the realization of substantial justice. In the absence of procedural, transnational principles and rules accepted universally, some national legislators and courts, in particu- 
lar the European Union, have had a laudable recourse to developing bilateral conflict rules of a procedural nature in order to meet the new challenges, in particular those relating to the characterization and the application of foreign law.

Keywords: sources of International Law, formalistic challenge, jurisdiction, competence and access to international justice, responsibility and reparation, jus cogens, exhaustion of local remedies, international terrorism, protection of the environment, human rights, lex fori regit processum, characterization, foreign law, bilateral conflict rules, substantive and procedural principles. 